\title{
MATCH QUALITY, WORKER PRODUCTIVITY, AND WORKER MOBILITY: DIRECT EVIDENCE FROM TEACHERS
}

\author{
C. Kirabo Jackson \\ Working Paper 15990 \\ http://www.nber.org/papers/w15990

\section{NATIONAL BUREAU OF ECONOMIC RESEARCH 1050 Massachusetts Avenue Cambridge, MA 02138}

May 2010

I thank John Abowd, Simon Woodcock, and Derek Neal for helpful suggestions. I thank Kara Bonneau of the North Carolina Education Research Data Center. All errors are my own. The views expressed herein are those of the author and do not necessarily reflect the views of the National Bureau of Economic Research.

NBER working papers are circulated for discussion and comment purposes. They have not been peerreviewed or been subject to the review by the NBER Board of Directors that accompanies official NBER publications.

(C) 2010 by C. Kirabo Jackson. All rights reserved. Short sections of text, not to exceed two paragraphs, may be quoted without explicit permission provided that full credit, including $(\mathrm{C}$ notice, is given to the source. 
Match Quality, Worker Productivity, and Worker Mobility: Direct Evidence From Teachers

C. Kirabo Jackson

NBER Working Paper No. 15990

May 2010, Revised February 2012

JEL No. I20,J01,J63

\begin{abstract}
$\underline{\text { ABSTRACT }}$
I investigate the importance of the match between teachers and schools for student achievement. I show that teacher effectiveness increases after a move to a different school, and I estimate teacher-school match effects using a mixed-effects estimator. Match quality "explains away" a quarter of, and has two-thirds the explanatory power of teacher quality. Match quality is negatively correlated with turnover, unrelated with exit, and increases with experience. This paper provides the first estimates of worker-firm match quality using output data as opposed to inferring productivity from wages or employment durations. Because teacher wages are essentially unrelated to productivity, this is compelling evidence that workers may seek high-quality matches for reasons other than higher pay.
\end{abstract}

C. Kirabo Jackson

Northwestern University

School of Education and Social Policy

2040 Sheridan Road

Evanston, IL 60208

and NBER

kirabo-jackson@northwestern.edu 


\title{
Match Quality, Worker Productivity, and Worker Mobility: Direct Evidence from Teachers
}

\author{
C. Kirabo Jackson ${ }^{1}$, Dec 23th 2011 \\ Northwestern University, IPR, and NBER
}

I investigate the importance of the match between teachers and schools for student achievement. I show that teacher effectiveness increases after a move to a different school, and I estimate teacher-school match effects using a mixedeffects estimator. Match quality "explains away" a quarter of, and has two-thirds the explanatory power of teacher quality. Match quality is negatively correlated with turnover, unrelated with exit, and increases with experience. This paper provides the first estimates of worker-firm match quality using output data as opposed to inferring productivity from wages or employment durations. Because teacher wages are essentially unrelated to productivity, this is compelling evidence that workers may seek high-quality matches for reasons other than higher pay.

The productive quality of the match between workers and firms plays a central role in canonical models of worker mobility (Jovanovic 1979, Mincer and Jovanovic 1981, Neal 1999, Burdett 1978, Mortensen 1998, Johnson 1978). The labor market is hypothesized to efficiently allocate workers to firms through workers leaving/seeking jobs where the productivity match between the worker and firm is low/high. Match quality is also used to explain the stylized facts that changing jobs is associated with earnings growth (Bartel and Borjas 1981, Altonji and Shakotko 1987, Topel and Ward 1992) and job separations decline with tenure and experience. ${ }^{2}$

Despite the importance of match effects for understanding the labor market, there is little direct evidence of their existence. Data on match-specific productivity are essentially nonexistent, forcing researchers to specify how wages relate to match-specific productivity and then study how wages and their distribution vary with tenure and job mobility (Nagypal 2007). This is undesirable for two reasons. First, there are many different ways to specify wage setting, making mis-specification and omitted variables bias likely. For example, taste-based discrimination can depress wages and increase job separations for certain workers at certain firms - mimicking empirical patterns consistent with productivity match effects. Second, it is difficult to distinguish workers leaving/seeking jobs with low/high match quality from workers leaving/seeking jobs with low/high pay because pay may vary across workers and firms for reasons unrelated to productivity. To avoid these problems, one must estimate match quality on actual output. Micro-

\footnotetext{
${ }^{1}$ I thank John Abowd, Simon Woodcock, and Derek Neal for helpful suggestions. I thank Kara Bonneau of the North Carolina Education Research Data Center. All errors are my own.

${ }^{2}$ By match quality, I am referring to the fixed time-invariant productivity associated with a particular worker-firm pairing. I am not referring to match quality that changes over time, such as that due to firm specific human capital.
} 
data with student test scores linked to teachers and schools provides a unique opportunity to estimate worker (teacher), firm (school), and match (a given teacher at a particular school) productivity on a measure of output (student achievement) directly.

Using a longitudinal dataset of student test scores linked to teachers and schools in North Carolina, I aim to (1) determine the extent to which teacher effectiveness, as measured by ability to improve student test scores, changes depending on the schooling environment, (2) quantify the importance of the match between a teacher and a school in determining student achievement, (3) document the relationship between match quality and teacher mobility, and (4) present evidence on observable characteristics associated with high match quality.

Match quality is of interest in its own right because we have little understanding of the role of school-teacher match quality for student achievement. Studies that identify teachers associated with student test-score gains show that a one standard deviation increase in teacher quality leads to between one-tenth and one-fifth of a standard deviation increase in math and reading scores (Aaronson, Barrow and Sander 2007, Rivkin, Hanushek and Kain 2005, Rockoff 2004). However, because observable teacher characteristic explain only a fraction of a teacher value-added $^{3}$, we have little understanding of exactly what they measure, and whether a teacher who is effective at one school (e.g. with affluent suburban kids) would be equally effective at another school (e.g. with low-income inner-city students). ${ }^{4}$ Given the increasing use of estimated teacher value-added to identify effective teachers, and policies that aim to move strong teachers from high-achieving schools into low-performing schools, it is important to understand the importance of school specific teacher value-added; that is, the importance of match quality. Moreover, it is also important to assess the importance of the teacher-school match itself. If match effects are economically important, policymakers should consider what kinds of teacherschool pairings are most productive and should consider the effect of policies on match quality.

I find that teachers who switch schools are more effective after a move than before suggestive of match effects. I present a variety of empirical tests showing that this cannot be explained by teachers moving to higher-achieving schools, endogenous teacher movement, or student selection. I use both a fixed effects model and a random effects model to estimate the

\footnotetext{
${ }^{3}$ There is evidence that years of experience, college selectivity, teachers' test scores, and regular licensure are associated with higher student achievement (Anthony and Goldhaber 2007, Brewer and Ehrenberg 1994, Brewer and Goldhaber 2000, Clotfelter, Ladd and Vigdor 2006, Clotfelter, Ladd and Vigdor 2007, Hanushek 1997)

${ }^{4}$ Ost (2009) finds that holding total experience constant, teachers with grade-specific experience have higher valueadded. This suggest that teacher value-added changes over time and may be context specific.
} 
importance of match quality. Across both models, one standard deviation increase in match quality increases math scores by about $0.09 \sigma$, and reading scores by about $0.07 \sigma$ - roughly twothirds the effect of a one standard deviation increase in teacher quality. Match quality can account for between 10 and 40 percent of what is typically estimated as teacher quality, so that a sizable portion of what is typically considered a teacher effect is not portable across schools. Exploratory data analysis reveals that certain identifiable kinds of teachers have much better outcomes at certain identifiable kinds of schools such that an optimal matching of teachers to schools could yield meaningfully improved outcomes overall.

Consistent with canonical models of job search, (a) among mobile teachers, match quality is higher in the new match than in the previous match, (b) general teacher quality is unrelated to switching jobs within teaching while match-specific quality is negatively correlated with switching teaching jobs, (c) while general teacher quality is negatively correlated with exiting the profession match-specific quality is unrelated to exiting the profession. These patterns are robust across estimation strategies and to the inclusion of both teacher and school fixed effects. The patterns suggest that match quality is an important determinant of mobility for reasons other than the level of pay because productivity and pay are largely unrelated for teachers. This is consistent with either schools providing greater non-pecuniary benefits for effective teachers or teachers caring about their effectiveness directly. As such, these findings suggest that models of worker mobility that do not account for non-pecuniary job benefits may be incomplete, and further underscore that using wages to infer match quality has some important limitations.

This is the first paper to validate the extant job search literature using direct measures of output, and the first to document the relationship between match quality and worker mobility in a context where wages and productivity are unrelated - underscoring the importance of nonpecuniary benefits. Also, this paper is the first to highlight and quantify the importance of match effects in education, and the first to document that a sizable portion of what we call teacher quality does not port across schools. The findings speak to the theoretical literature on job search and the empirical literature on teacher quality, and have important policy implications.

The remainder of this paper is as follows. Section I outlines the empirical framework behind estimating match effects and lays out a theoretical framework based on Jovanovic (1979). Section II describes the data. Section III provides evidence of match effects. Section IV describes the estimation strategies and presents estimates of the variability of teacher, school, and match 
effects. Section V tests the theoretical predictions regarding the relationship between match quality and teacher mobility. Section VI presents evidence on what kinds of teacher-school combinations are associated with higher match quality, and Section VII concludes.

\section{Match Quality for Teachers}

The literature that decomposes wages into a worker effect and a firm effect starts out with a Cobb-Douglas production function describing the output $Q_{i j}$ of worker $i$ at firm $j$ as below. ${ }^{5}$

$$
Q_{i j}=L_{i}^{\theta} K_{j}^{\varphi} .
$$

In (1), $L_{i}$ is the human capital of worker $i$ (such as education, years of experience, quality of schooling, etc), $K_{j}$ summarizes the productive characteristics of the firm (such as technology, capital intensity, incentive structure, leadership skills, etc), and $\theta$ and $\varphi$ are parameters in the production function. Where certain worker and firm attributes are complementary certain pairings of workers and firms are relatively more or less productive. This is incorporated in the model with the inclusion of a match term $M_{i j}$ (Woodcock 2008) yielding (2) below.

$$
Q_{i j}=L_{i}^{\theta} K_{j}^{\varphi} M_{i j}^{\phi} .
$$

Where worker $i$ 's wage at firm $j$ is a share $\pi_{i j}$ of output, the log of worker wages is given by (3) which is comprised of four additively separable components; one due to worker productivity $\theta \ln L_{i}$, one due to workplace productivity $\varphi \ln K_{j}$, one due to the productivity match between the worker and firm $\phi \ln M_{i j}$, and the relative bargaining power of worker $i$ at firm $j \ln \pi_{i j}$.

$$
\ln w_{i j}=\theta \ln L_{i}+\varphi \ln K_{j}+\phi \ln M_{i j}+\ln \pi_{i j} .
$$

If differences in bargaining power across worker-firm pairings exist, relative productivity and match-specific relative bargaining power may be confounded. For example, if some discriminating firms pay equally productive female workers less than their male counterparts this would result in low $\ln \pi_{i j}$ for female workers at such firms. This discrimination could also be associated with poor treatment which would lead to increased job separation among females at such firms, leading one to wrongly infer a relationship between match quality and worker mobility based on wages. To further complicate matters, many theories of wage determination predict that wages have little relation to contemporaneous productivity. Furthermore, important

\footnotetext{
${ }^{5}$ See Abowd et. al. 2002, 1999, 2004.
} 
parts of worker compensation such as working conditions, in-kind benefits, and deferred compensation are typically not measured. For these reasons, using wage data to infer match quality has inherent limitations. This motivates the use of teacher (worker) data linked to schools (firms) and student outcomes (a direct measure of output).

\section{I.2 The Production of Student Achievement}

Consider the following model where student achievement is a function of the entire history of school and parental inputs and a student's endowment.

$$
T_{i j s a}=T_{a}\left[X_{i j s}(a), \mu_{i 0}, \varepsilon_{i j s a}\right] .
$$

In (4) $T_{i j s a}$ is student $i$ 's achievement with teacher $j$ at school $s$ at age $a, X_{i j s}(a)$ is the history of parental and school inputs up to age $a, \mu_{i 0}$ is the student's endowment (ability) and $\varepsilon_{i j s a}$ is an idiosyncratic error (other inputs). With additive separability of inputs and where lagged achievement is a summary statistic for the full history of family, school, and student inputs, we can write (4) as the commonly used value-added model described by (5) below. ${ }^{6}$

$$
T_{i j s a}=X_{i j s a} \alpha+\gamma T_{i a-1}+\eta_{i j s a}
$$

While there are many specifications that one could use, the predictive power of estimated teacher effects are surprisingly robust across specifications (Kane and Staiger 2008). Explicitly incorporating teacher human capital, school technology, and the productivity of the specific teacher-school pairing as inputs into the model yields (6) below.

$$
T_{i j s a}=\gamma T_{i a-1}+X_{i j s a} \alpha+\theta_{j}+\theta_{s}+\theta_{s j}+\eta_{i j s a} .
$$

Both equations (3) and (6) contain additively separable components; one due to worker (teacher) productivity $\theta_{j}$, one due to workplace (school) productivity $\theta_{s}$, and one due to the match between the worker and the firm $\theta_{j s}$. However, unlike (3), in (6) the school, teacher, and match components reflect differences in actual productivity, and there is no problematic unobserved relative bargaining power of the worker and their firm. As such, the use of education data where output is observed may validate previous studies on match quality and may provide new insights.

\subsection{Identifying Match Quality Empirically}

With data on multiple teachers at multiple schools, one can estimate match (teacher-byschool) effects separately from teacher effects and school effects. Consider the ideal empirical

\footnotetext{
${ }^{6}$ This will be true if coefficients on inputs are geometrically declining with distance (in age), and the impact of the ability endowment is geometrically declining at the same rate as inputs (Todd and Wolpin 2003).
} 
setup where each teacher is observed in all schools, and there is zero correlation between potential match, teacher, and school effects. ${ }^{7}$ Under these conditions, mean match quality for each teacher is zero, and mean match quality for each school is zero so that mean scores (conditional on controls for selection) of teacher $j$ at school $s$ would be a consistent estimate of match (teacher-by-school) effect $\theta_{j s}$. Also, the mean of the matches for teacher $j$ (across schools) would be a consistent estimate of teacher effect $\theta_{j}$, and the mean of matches for school $s$ (across teachers) would be a consistent estimate of school effect $\theta_{s}$. One could obtain consistent estimates of teacher, school, and match effects with the a fixed-effects estimator.

Identification of match effects comes from the fact that multiple teachers are observed switching across the same set of schools. To make this clear, consider two schools A and B and two teachers $p=\{1,2\}$. The difference in outcomes when teacher $p$ switches from school A to school B is $\left(\theta_{B}-\theta_{A}\right)+\left(\theta_{p B}-\theta_{p A}\right)$. This reflects the difference in school effects between school $\mathrm{A}$ and $\mathrm{B}$, plus the difference in match effects for teacher $p$ between schools A and B. If there are no match effects, then $\theta_{1 B}-\theta_{1 \mathrm{~A}}=0$, and the difference in expected outcomes associated with switching from A to B is equal to the difference in school effects only, and is the same for both teachers. With no match effects $E\left[\bar{Y}_{1 B}-\bar{Y}_{1 A}\right]-E\left[\bar{Y}_{2 B}-\bar{Y}_{2 A}\right]=\left(\theta_{B}-\theta_{A}\right)-\left(\theta_{B}-\theta_{A}\right)=0$. However, with match effects, expected differences associated with switching from schools will not be the same for both teachers so that $E\left[\bar{Y}_{1 B}-\bar{Y}_{1 A}\right]-E\left[\bar{Y}_{2 B}-\bar{Y}_{2 A}\right] \equiv \theta_{1 B}-\theta_{1 A}-\left(\theta_{2 B}-\theta_{2 A}\right) \neq 0$.

This shows that systematic performance differences associated with switching schools across teachers is how match effects can be identified empirically. ${ }^{8}$ The intuition can be illustrated with a simple example. Suppose school A has a strong principal who, all else equal, improves the outcomes of all teachers by $\delta$. School A enrolls high-income students while school B enrolls average students. Teacher 1 teachers performs $\mu_{1}$ better with high-income students while teacher 2 performs $\mu_{2}$ worse (where $\left|\mu_{2}\right|>|\delta|$ ). When teacher 1 switches from school B to$$
\operatorname{Cov}\left[\begin{array}{l}
\theta_{s} \\
\theta_{j} \\
\theta_{j s}
\end{array}\right]=\left[\begin{array}{ccc}
\sigma_{\theta s}^{2} I_{S} & 0 & 0 \\
0 & \sigma_{\theta j}^{2} I_{J} & 0 \\
0 & 0 & \sigma_{\theta j}^{2} I_{M}
\end{array}\right] .
$$

${ }^{7}$ Mathematically this condition means that

${ }^{8}$ With the assumptions that the mean of the match effects is equal to zero in expectation for each school and for each teacher these match estimates above can be computed. Specifically, these assumptions mean that in large samples $\theta_{1 B}+\theta_{1 A}=0$ and $\theta_{2 B}+\theta_{2 A}=0$ and $\theta_{1 B}+\theta_{2 B}=0$ and $\theta_{1 A}+\theta_{2 A}=0$. With four equations and four unknowns there is a unique solution for the values of the match effects.
} 
A, her outcomes are $\delta+\mu_{1}$ better in school A than B. However, when teacher 2 switches from school B to A, her outcomes are $\delta$ - $\mu_{2}$ worse. Even though there is a positive school effect $\delta$ enjoyed by both teachers, the difference in outcomes associated with switching schools is not the same because the match effect for school A is positive for teacher 1 and negative for teacher 2 . This differential switching response is the basis for indentifying match effects in this paper.

The discussion above assumes that all teachers are observed in all schools. In reality, most teachers are observed in just a few schools. While this complicates estimation of match effects, the logic of the identification is most saliently illustrated in this idealized setting. In section IV, I detail an approach to consistently estimate match effects outside of an ideal setting.

\section{I.4 How Does One Interpret Match Quality for Teachers?}

While it is difficult to disentangle a school or teacher with a large effect from a school or teacher that has high quality matches empirically, these concepts are distinct. A match effect is anything that makes a teacher more or less productive at one school versus another that is not due to a school characteristic that affects all teachers equally. Anything that affects all teachers at a school equally would be part of a school effect (e.g. high-achieving students, or strong leadership) and only those combinations of characteristics that vary at the teacher-by-school level are part of a match effect. Such effects arise when there is heterogeneity in the marginal effectiveness of school inputs across teachers. For example, certain teachers may be good at teaching certain types of students (e.g. same race, high-motivation) that attend certain schools. Alternatively, certain schools may have a work culture in which certain teachers thrive and others do not. There may be differences due to differential responses to the characteristics of other employees (e.g. experienced teachers, high value-added teachers). Note that teacher peer effects such as those found in (Jackson and Bruegmann 2009) will be part of a school effect and will only be a match effect if some teachers are more responsive to the quality of their peers than others. In sum, match quality captures systematic complementarities between particular teachers and particular schools. I present the correlates of high/low match quality in section VI.

\section{I.5 Theoretical Framework}

Most theories of match quality are predicated on the notion that workers seek out high quality matches in order to increase their monetary compensation. However, teacher salaries are based primarily on years of experience and level of education. In this section I present a framework to explain how and why match quality may be related to mobility for teachers. 
The theoretic framework follows (Jovanovic, 1979). There is imperfect information about which matches are more or less productive and when a teacher searches for a job she receives a random draw from a known distribution of match quality. Match quality is an experience good so that only after a match is made is the quality of the match revealed to the employee and all employers. Employers can contract with workers on an individual basis and are able to reward a worker with whom he matches well by improving the worker's total job-related utility. Unlike canonical models, I assume that employers can improve job-related utility not only by altering wages but also by altering the non-wage aspects of compensation. ${ }^{9}$ For example, principals can assign teachers to more desirably committees, offer them extra positions to supplement their income, pay for more of their training costs, or appoint them to positions of leadership. Given that teachers often spend money out of pocket to pay for classroom supplies, another way principals can, and do, effectively increase teacher pay without giving a "raise" is to pay for such supplies. ${ }^{10}$ Even without action on the part of employers workers may also seek high productivity matches because they derive utility directly from being productive. ${ }^{11}$ In this framework, workers well-matched with their employers are less likely to quit either due to employers increasing job related utility or due to non-pecuniary job characteristics. Because information about match quality is revealed after being employed at a school, teachers who realize that they are poorly matched have an incentive to leave their current job (select out of bad matches) and take a new draw from the known distribution of matches. Because having a bad match is indicative of being bad at a particular school but not the profession as a whole, low match quality should be associated with switching schools, but not be related to leaving teaching.

In addition to match-quality which is specific to a particular teacher-school pairing, teachers also have general teaching ability that is transferable across schools (but not necessarily across occupations). Similar to match quality, general teaching ability is an experience good that

\footnotetext{
${ }^{9}$ Going as far back as Adam Smith it has been recognized that the utility a worker derives from their job is associated with more than monetary compensation. As stated by Smith "Wages vary by ease vs. hardship, cleanliness, honourableness." (Smith, Adam. 1776. Wealth of Nations. Chicago: University of Chicago Press). This is illustrated by the fact that the unemployed are much less happy than the employed, and by more than their lower incomes would predict (Korpi 1997; Winkelmann and Winkelmann 1998; Di Tella, MacCulloch, and Oswald 2001) and that one's ordinal rank in the wage hierarchy affects one's happiness conditional on ones level of pay (Brown, Gardner, and Oswald, 2006). Aside from consumption aspects of the job, in-kind benefits make up a substantial part of a worker's compensation, and workers care about working conditions and prestige (Duncan, 1976).

${ }^{10}$ The average teacher surveyed for the 2010 Retail Market Awareness Study released by the National School Supply and Equipment Association said they spent \$936 on classroom materials in the 2007 academic year.

${ }^{11}$ Insofar as teachers have some intrinsic motivation to teach and believe in service, they may be willing to trade off monetary rewards for the non-pecuniary gains of being of service as discussed in Akerlof and Kranton (2005).
} 
is only revealed to all parties after entering the teaching profession. Because low general teaching quality is indicative of being bad in the profession, teachers with low general teaching ability should be more likely to exit the profession entirely. However, because teaching ability is a general skill, it should not be associated with school switching within the teaching profession.

This framework generates predictions that can be taken to the data; (1) among mobile teachers, match quality should be higher in the new match than in the previous match, (2) higher general teacher quality should be negatively correlated with exiting the profession, (3) general teacher quality should be uncorrelated with switching, (4) higher match specific quality should be negatively associated with switching, (5) match quality should be unrelated to exiting the profession. A number of studies have found that effective teachers are less likely to exit teaching or transfer schools (Jackson 2010; Hanushek et. al. 2005; Sass and Feng 2011; Sass, et. al. 2011). These patterns are consistent with the predictions above. However, these studies do not distinguish between teacher quality and match quality so that testing these predictions may put these documented patterns into theoretical context.

\section{Data}

This paper uses data on all third-grade through fifth-grade students in North Carolina from 1995 to 2006 from the North Carolina Education Research Data Center. ${ }^{12}$ The student data include demographic characteristics, standardized test scores in math and reading, and codes allowing one to link the student test score data to information about the schools the students attend and the teachers who administered their tests. Discussions with education officials in North Carolina indicate that tests are always administered by the students' own teachers when these teachers are present. To limit the sample to teachers who I am confident are the students' actual teachers, I include only students who are being administered the exam by a teacher who teaches math and reading to students in that grade. I also remove teachers who are co-teaching or have a teaching aide. This process yields roughly 1.37 million student-year observations. Summary statistics for these data are presented in Table 1.

The students are roughly 62 percent white 30 percent black, and are evenly divided between boys and girls. About 11 percent of students' parents did not finish high school, 43

\footnotetext{
${ }^{12}$ These data have been used by other researchers to look at the effect of teachers on student outcomes (Clotfelter, Ladd and Vigdor 2006, 2007) and the effect of student demographics on teacher quality (Jackson 2009).
} 
percent had just a high school diploma, 30 percent had some post-high school education, and 14 percent had parents with a four-year degree or higher. The average class size is 23. Reading and math scores are standardized in each grade-year cell to have a mean of zero and unit variance.

About 92 percent of teachers is the sample are female, 83 percent are white, and 15 percent are black. The average teacher in the data has thirteen years of experience, and roughly 6 percent of the teachers have no experience. ${ }^{13}$ Roughly 20 percent of teachers have advanced degrees. About 67 percent of the teachers in the sample have regular licensure as opposed to working under a provisional, temporary, emergency, or lateral entry license. I normalize scores on the Elementary Education or the Early Childhood Education tests that all North Carolina elementary school teachers are required to take, so that these scores have a mean of zero and unit variance for each year in the data. Teachers perform near the mean, with a standard deviation of 0.81. About 4 percent of teachers have National Board Certification.

There are 27,498 teachers and 1545 schools in the final dataset. The average school is observed with 21.3 teachers while about 80 percent of teachers are observed in only one school. About 16 percent of teachers are observed in two schools, 2 percent in three schools, and about 1 percent in four or more schools. The average teacher is observed in the data for 3.26 years, and about 37 percent are observed for one year. There are 32,922 teacher-school matches observed in the data, and each match contains data from about 98 students and 4.2 classrooms, on average. Matches for mobile teachers contain on average 78 student observations and 3.4 classrooms.

\section{II.1 Who are the mobile teachers?}

Because match quality is a within-teacher concept, match effects can only be estimated for mobile teachers and may not be representative of match effects for non-mobile teachers. While this does not affect the internal validity of the exercise, one may wonder how mobile teachers compare to the average teacher. To gain a sense of this, I estimate linear probability models for the likelihood that a teacher switches to another school next year, as a function of observable teacher characteristics. I estimate the (7) below by Ordinary Least Squares (OLS).

$$
Y_{j s t}=T_{j t} \beta+\tau_{t}+\varepsilon_{j s t}
$$

In (7), $Y_{j s t}$ is whether teacher $j$ switches from her current school $s$ at time $t, T_{j t}$ are time varying teacher characteristics, $\tau_{t}$ is a year fixed effect, and $\varepsilon_{j s t}$ is the idiosyncratic error term. I present

\footnotetext{
${ }^{13}$ Teacher experience is based on the amount of experience credited to the teacher for the purposes of determining salary; therefore, it should reflect total teaching experience in any school district.
} 
these results in column 1 of Table 2. These estimates are descriptive; I model teacher switching and exiting the profession formally in Section $\mathrm{V}$.

Column 1 shows that the likelihood of switching schools is monotonically decreasing in experience- consistent with more experienced teachers finding better matches and remaining in these schools. On average, teachers with higher licensure scores and teachers with an advanced degree are no more likely to switch schools, while those with a regular teaching license are 4.2 percentage points more likely to switch schools. Because these relationships could reflect the fact that mobile teachers differ from non-mobile teachers in their school locations, and certain schools have higher teacher turnover than others, the estimates in column 2 includes school fixed effects. The patterns are similar. In sum, the sample of switchers are most likely to have fewer than 10 years of experience, less likely to have more than 24 years of experiencing, and more likely to be regularly licensed teachers than the average teacher.

\section{II.2 How do destination schools differ from sending schools?}

Because a large part of the analysis involves comparing teacher performance in one school to their performance in another, it is instructive to describe how the schools teachers move to differ from those they leave. I present the difference in school characteristics between a teacher's school the year before and after she switches schools. For each characteristic $X_{i j}$ for teachers who switch schools in year $t$, I present $\Delta X_{i j}=X_{i j ' t-1}-X_{i j t}$, and I test for the statistical significance of these differences. To see if the patterns of school switching are different for different kinds of teachers, I present theses differences for all teachers, and also for sub-samples of teachers. These comparisons are presented in Table 3.

On average teachers move to schools where mean school level reading test scores are $0.023 \sigma$ higher, and classes are 0.23 students smaller. Also, teachers move to schools where the percentage of black and low-income students in the school is 2.5 and 3.8 percentage points lower, respectively. Teachers also experience a 7.3 percent pay increase after a move. Teachers are not switching out of large cities into other areas, but they are more likely to switch out of schools in mid-sized cities and towns into rural areas. The patterns here are consistent with teachers leaving low-performing schools that serve low-income ethnic-minority students for higher-achievement schools with fewer low-income students and fewer minority students.

Columns 2 and 3 show results for white and non-white teachers, respectively. While all teachers experience a pay increase and go to schools with fewer low-income students after a 
move, white teachers go to schools with higher-achieving students and more white students, while non-white teachers move to schools that have similar levels of achievement and more black students. Also, similar to findings in Hanushek, Kain and Rivkin (2004) using Texas data, non-white teachers are more likely to switch into inner-city schools while white teachers are not. Teachers with high scores experience larger increase in student achievement, smaller decreases in the percentage of black students, and are less likely to move into a less urbanized environment after a move than low scoring teachers. Inexperienced teachers (fewer than 5 years) experience larger increases in student achievement after a move than do veteran teachers (more than 10 years). All groups tend to leave schools with low-income students, but inexperienced teachers see larger decreases in the percent black at their new school than experienced teachers. While inexperienced teachers appear to be switching largely out of towns, experienced teachers are switching out of mid-sized cities and urban fringes. In sum, not all teachers are switching to or from the same schools, so that several schools have different teachers switching in and out. This fact plays a central role in my identification strategy.

\section{Preliminary Evidence of the Existence of Match Effects}

The first empirical prediction from the theoretic framework predicting that teachers are more likely to leave bad matches, is that match quality should be higher in a new match than in a previous match so that teachers should be relatively more effective after than before switching schools. I can test this first prediction empirically by mapping-out teacher effectiveness before and after a move. To do this, I estimate (8) by OLS. ${ }^{14}$

$$
T_{i j s y}=\gamma T_{i y-1}+X_{i j s y} \alpha+\sum_{\tau=-10}^{9} I_{t=\tau} \cdot \pi_{\tau}+\theta_{j}+\eta_{i j s y} .
$$

In (8) $T_{i j s y}$ is student $i$ 's achievement with teacher $j$ at school $s$ in year $y, X_{i j s y}$ is a vector of control variables (student race, gender, parental education, limited English proficiency, the gender and racial match between the student and the teacher, class size, and teacher experience), and $\theta_{j}$ is a teacher fixed-effect. Because one cannot simultaneously estimate teacher, year and experience effects $^{15}$, as is common, I include indicator variables for experience bins $(0,1$ to 3,4

\footnotetext{
${ }^{14}$ Equation (8) follows naturally from equation (7), where the age subscript for the student is replaced with the more general year subscript that is defined for teachers, schools, and students.

${ }^{15}$ This is pointed out in Rockoff (2004) and (Papay and Kraft 2010).
} 
to 9,10 to $24,25+$ ). In (8) $\pi_{\tau}$ is the effect of having a teacher who is $\tau$ years from leaving her current school (for example $\pi_{-2}$ is the effect for a teacher who will leave her current school in 2 years and $\pi_{+2}$ is the effect for a teacher who left another school two years ago). The reference year is the year before a teacher switches schools. In this Difference in Difference (DID) model, the "years before/after move" variables map out changes in outcomes for teachers who switch schools relative to changes for teachers who do not switch schools over the same time period. ${ }^{16}$

To ensure that any pre- and post-move differences are not driven by unmeasured achievement differences across schools, I can estimate equation (8) including school fixedeffects. In such models, none of the effects can be driven by level differences across schools that affect all teachers equally (as this is absorbed by the school effect). As such, any within-teacher differences in performance associated with a move across schools must be due to a differential response to schools across teachers (i.e. match effects). While including school fixed-effects removes mean differences across schools, one may also worry that time varying school characteristics affect both teacher performance and teacher mobility. For example, if a school experiences some negative shock in year $t-1$, this may cause some teachers to have poor performance in year $t-1$ and leave the school in year $t$. This could lead one to wrongly infer that teachers are more effective after a move than before. To address this issue, I estimate models that include a year fixed effect for each school so that comparisons are made among teachers at the same school in the same year, to control for any school-specific events that may affect both teacher effectiveness and teacher mobility. To map-out teacher effectiveness over time while accounting for time varying differences in outcomes across schools, I estimate (9) by OLS.

$$
T_{i j s y}=\gamma T_{i y-1}+X_{i j s y} \alpha+\sum_{\tau=-10}^{9} I_{t=\tau} \cdot \pi_{\tau}+\theta_{j}+\theta_{s \times y}+\eta_{i j s y} .
$$

All variables are defined as before and $\theta_{s \times y}$ is a school-by-year fixed effect. Because this model includes both school-by-year and teacher fixed effects, this DID model compares a teacher's outcomes before and after a move while accounting for average outcomes of the schools (in a particular year) she moved to and from.

\footnotetext{
16 Teacher switching is defined within the sample. This definition of switching captures 72 percent of all switching that takes place in the data. This ensures that the before/after comparisons are really a within teacher concept. As such a teacher with only pre-move data or a teacher with only post-move data will not be included in the mobility analysis variables. Similarly, is a teacher switches from 3rd grade at one school and then 2nd grade at another school and then starts teaching 3rd grade in the new school 2 years later, she will enter the data in all the pre-move years and then again in the third post move year.
} 


\section{A Test for Endogenous Teacher Mobility}

In all papers on worker mobility there is the concern that productivity is endogenous to worker mobility. Note that teachers switching because their performance is poor is not endogenous mobility in this context and is exactly the kind of mobility I aim to characterize. The worry would be if productivity is endogenous to the switch. Specifically, the worry is that if teachers anticipate that they will leave their current job in one year, they may reduce their effort the year before a move to a new school. In such a scenario, one would observe that productivity is low before a move and wrongly infer that a teacher was leaving a low productivity match. In this scenario, one would expect teacher effectiveness to be uncharacteristically low one or two years immediately prior to a switch. By the same argument, if teachers aim to impress those at their new school, they may exert more effect temporarily right after a move and seem more productive at their new school. In this scenario, one would expect teacher effectiveness to be uncharacteristically high one or two years immediately after a switch, and for there to be some systematic pattern in teacher effectiveness after the first year a teacher moves. Under these scenarios there is some systematic pattern in teacher effectiveness prior to, or after, a move. As such, the finding that individual years before/after a move variables have no explanatory power over a simple pre vs. post model would suggest that effectiveness is exogenous to mobility.

\section{III.1 Findings}

The "years until/since move" indicator variable coefficient estimates from equations (8) and (9) are presented in Table 4 and visually in Figure 1. The basic within-teacher results show that teachers perform better after a switch than before. Relative to the year before a move, all the post-move indicator variables have positive coefficients for both subjects, while the pre-move indicator variables are either negative or close to zero and positive. This is indicative of the existence of match effects, and shows that teachers move from schools where the productivity of the match between them and the school is low. ${ }^{17}$ The point estimates suggest that at a teacher increases test scores by about 2.5 percent and 1.4 percent of a standard deviation more at her new school than at her old school in math and reading, respectively (columns 2 and 6 ). ${ }^{18}$ Results that

\footnotetext{
${ }^{17}$ Results are similar in models that include smaller bin sizes and also models that control for teacher experience parametrically with a second order polynomial. Moreover, if these estimates merely reflected an experience effect they would not be relatively larger in the exact same year of a move than all other years. There would be a greater concern for bias due to an experience effect if the model were simply a before/after model.

${ }^{18}$ Columns 1 and 5 show the results with test score growth as the dependent variable with teacher fixed effects for math and reading, respectively. The results are largely unchanged. This is to deal with the worry that measurement
} 
also include school fixed effects, or school-by-year fixed effects are very similar-indicating that the estimated outcome differences before and after a move are not spuriously driven by teachers moving from low- to high-achievement schools and not driven by school-wide events that would affect both teacher mobility and teacher performance.

For both subjects there is little evidence of endogenous teacher mobility even though teacher effectiveness is significantly different after a move than before. In the preferred models, for both subjects one cannot reject the null hypothesis that all pre-move year effects are the same and that all the post move years are the same at the 20 percent level, while one rejects that pre and post move performance is the same at the 1 percent level. This is consistent with the relatively uniform effectiveness before a move the one time upward shift in effectiveness after a move and the relatively uniform effectiveness after a move depicted in Figure 1.

\section{Could dynamic student selection drive these results?}

Readers may worry that sorting of students could drive the results if (a) students who are assigned to teachers who will leave the school the following year are systematically worse in unobserved dimensions than those who are not, and/or (b) students who are assigned to teachers at the teacher's new school are better in unobserved dimensions. The fact that there are no pre- or post- move trends in outcomes is prima-facie evidence that this is not driving the results. However, to test for student sorting in unobserved dimensions directly, one can see if (a) students in year $y$ who will receive a teacher in year $y+1$ who will leave the school between year $y+1$ and $y+2$ have worse outcomes than those who will not, and (b) if students in year $y$ who will have a teacher in year $y+1$ that transferred from another school between years $y$ and $y+1$ have better outcomes than those who do not. To do this I estimate a model similar to equation (9) but adding indicators for the mobility status of a student's future teacher (the year $y+1$ mobility status of a student's time $y+1$ teacher). The coefficient on the variable denoting whether the student's teacher next year will leave the following year is 0.001 ( $p$-value $=0.74$ ), and the coefficient on a variable denoting whether the student's teacher next year will be a new transfer from another school is 0.002 ( $p$-value $=0.26)$ - both close to zero. As such, it appears that the improved outcomes observed after a teacher switches schools is not an artifact of dynamic student sorting and likely reflects teachers schools with which they are poorly matched.

error in a lagged dependent variable can lead to bias in a quasi-differenced model. 


\section{Estimating Match Effects and Estimating the Importance of Match Effects}

As discussed in Section 1.4, in the ideal empirical setup, after accounting for possible student selection, the mean of all the matches for teacher $j$ (across schools) would be a consistent estimate of the teacher effect $\theta_{j}$, the mean of all the matches for school $j$ (across teachers) would be a consistent estimate of the school effect $\theta_{s}$, and the mean for teacher $j$ at schools $s$ would be a consistent estimate of the match effect $\theta_{j s}$. However, because teachers are typically observed in only a few schools, it is unlikely that match effects average out to zero for each teacher. This will lead to small sample bias in the teacher, school, and match effect estimates. In this section, I present a fixed effects strategy and detail these shortcomings. Motivated by the limitations of the fixed-effects approach, I also present an Empirical Bayes random effects strategy that does not rely on large sample properties. I highlight important differences between the two, and show that the main conclusions do not hinge on how one estimates school, teacher, and match effects.

\section{IV.1 Orthogonal Match Fixed Effects}

The first approach is to estimate orthogonal match fixed effects. To do this I estimate (10) below (a model with school fixed effects and teacher fixed effects) and define the match effect for each teacher-school pair, $\bar{e}_{j s}$, as the mean value of the residual for teacher $j$ at school $s$.

$$
T_{i j s y}=\gamma T_{i y-1}+X_{i j s y} \alpha+\theta_{j}+\theta_{s}+\eta_{i j s y} .
$$

Because match effects are computed from residuals, the estimated match effects are orthogonal to teacher and school effects, the mean match quality for each teacher is equal to zero, and the mean match quality for each school is equal to zero by construction.

This approach, while straightforward, has the undesirable feature that it mechanically loads match quality that is correlated with the teacher or school effects (in small samples) on to the teacher or school effects, respectively. This makes it impossible to determine how much of what we estimate as a teacher effect may be a match effect, and will overstate the importance of teacher and school effects while understating the importance of match effects. However, while their magnitude may be understated, orthogonal match effects do have the intuitive interpretation of being the observed within-teacher variation in performance that can be attributed to working in different school environments for mobile teachers. I detail how to uncover estimates of the variance of true teacher, school, and match quality in a fixed effects framework below.

\section{Fixed Effect Based Estimates of the True Variance}

Because the raw fixed effect estimates are estimated with noise, the variance of the 
estimated effects will not accurately reflect the variance of true teacher, school, and match quality. As such, I estimate a series of covariances across classrooms to remove the contribution of idiosyncratic year-specific shocks (such as a dog barking on the day of the test) and random sampling variation to uncover the true variability of teacher, school, and match effects. This is done in two steps. First, I estimate an achievement model like (11) with teacher-by-school-byyear fixed effects (i.e. classroom fixed effects).

$$
T_{i j s y}=\gamma T_{i y-1}+X_{i j s y} \alpha+\theta_{j s y}+\eta_{i j s y} .
$$

The classroom fixed effect term $\theta_{j s y}$ contains a piece attributed to the school, the teacher, the match between the teacher and the school, and idiosyncratic year-specific shocks (that is $\left.\theta_{j s y} \equiv \theta_{s}+\theta_{j}+\theta_{j s}+\lambda_{j s y}\right)$. Under the assumption that the idiosyncratic shocks, the teacher, school, and match effect are all uncorrelated in the data, one can estimate the variance of the teacher, school, and match effects with a series of covariances. Specifically, the covariance of classroom effects one year apart within teachers and across schools is the variance of the persistent teacher component common across schooling environments, $\operatorname{Cov}\left(\theta_{j s y}, \theta_{j s^{\prime} y+1}\right) \equiv \sigma_{j}^{2}$. Similarly, the covariance of classroom effects one year apart across teachers and within schools is the variance of the persistent school component common to all teachers, $\operatorname{Cov}\left(\theta_{j s y}, \theta_{j^{\prime} s y+1}\right) \equiv \sigma_{s}^{2}$. Finally, the covariance of classroom effects one year apart within teachers and within schools is the variance of the persistent teacher component, the common school component and the component specific to the match between teachers and schools, $\operatorname{Cov}\left(\theta_{j s y}, \theta_{j s y+1}\right) \equiv \sigma_{s}^{2}+\sigma_{j}^{2}+\sigma^{2}{ }_{j s}$. As such, one can obtain an estimate of the variance of match effects from $\operatorname{Cov}\left(\theta_{j s y}, \theta_{j s y+1}\right)-\operatorname{Cov}\left(\theta_{j s y}, \theta_{j s^{\prime} y+1}\right)-\operatorname{Cov}\left(\theta_{j s y}, \theta_{j^{\prime} s y+1}\right) \equiv \sigma_{j s}^{2}$. For comparison purposes, I present naive estimates of the variance of teacher effects under the assumption of no match effects. Specifically, if there were no match effects then the covariance across classrooms for the same teacher at the same school will only reflect the teacher effect and the school effect so that $\sigma_{j}^{\text {naive }}=\operatorname{Cov}\left(\theta_{j s y}, \theta_{j s y+1}\right)-\operatorname{Cov}\left(\theta_{j s y}, \theta_{j^{\prime} s y+1}\right)$. Because these estimates assume that match quality and teacher quality are uncorrelated in the data, these estimates understate the importance of matches 
and may overstate that of teachers. ${ }^{19}$ This motivates my use of a maximum likelihood approach.

\section{IV.2 Maximum Likelihood Random Match Effects}

The second approach is to estimate random match effects. For this, one estimates teacher, school, and teacher-by-school effects simultaneously using a mixed-effects estimator. This is done in two steps. First, I estimate a model like (12) with teacher-by-school fixed effects $\mu_{j s}$.

$$
T_{i j s y}=\gamma T_{i y-1}+X_{i j s y} \alpha+\mu_{j s}+\eta_{i j s y} .
$$

Note that by estimating a model with teacher-by-school effects I do not assume that the teacher, school, and match effects are uncorrelated with the included covariates. Then, I take the combined error term $\mu_{j s}+\eta_{i j s y}$ (the teacher-by-school effect and the idiosyncratic error term) and estimate a random effects model to decompose the combined residual into a school effect, a teacher effect, and a teacher-by-school effect. To account for teacher-school-year or classroom effects (e.g. a flu outbreak that affects the scores of the whole class), I allow for a teacher-schoolyear level error $\theta_{j s y}$. This is important insofar as one does not observe teachers for many years at a particular school. In the extreme, if one observes a teacher for only one year in a school, it is impossible to disentangle match effects from idiosyncratic year-specific shocks unless one account for this additional source of variability.

The random effects estimator estimates the variances of the teacher, school, match, and classroom effects by Maximum Likelihood under the assumptions of joint normality with the covariance structure described in (13), that the random effects are uncorrelated with the covariates conditional on the estimated first stage coefficients described in (14), and the fixed effects identifying assumption that the error term $\eta_{i j s y}$ is uncorrelated with the random effects.

$$
\begin{aligned}
& \operatorname{Cov}\left[\begin{array}{c}
\theta_{s} \\
\theta_{j} \\
\theta_{j s} \\
\theta_{j s y}
\end{array}\right]=\left[\begin{array}{cccc}
\sigma_{\theta s}^{2} I_{S} & 0 & 0 & 0 \\
0 & \sigma_{\theta j}^{2} I_{J} & 0 & 0 \\
0 & 0 & \sigma_{\theta j s}^{2} I_{M} & 0 \\
0 & 0 & 0 & \sigma_{\theta j s y}^{2} I_{C}
\end{array}\right] . \\
& E\left[\theta_{s} \mid \hat{\gamma}, \hat{\alpha}, T, X\right]=E\left[\theta_{j} \mid \hat{\gamma}, \hat{\alpha}, T, X\right]=E\left[\theta_{j s} \mid \hat{\gamma}, \hat{\alpha}, T, X\right]=E\left[\theta_{j s t} \mid \hat{\gamma}, \hat{\alpha}, T, X\right]=0
\end{aligned}
$$

Similar to the orthogonal match fixed effects approach, teacher, school, and match effects are identified largely by mobile teachers. However, unlike the orthogonal match approach that

\footnotetext{
${ }^{19}$ For example, if a teacher has two good matches, this covariance approach will attribute covariance across schools to the persistent teacher effect when in fact the matches are positively correlated in sample. With a large number of matches per teacher, this would not pose a problem. However, in small samples this leads to biased estimates.
} 
assumes that the actual match, school, and teacher effects observed in the data are uncorrelated, the random match effects approach assumes that the potential match, school, and teacher effects (that one would observe if all teachers were observed in all schools) are uncorrelated, but that the actual match, school, and teacher effects observed in small samples (where teachers are observed in few schools) can be correlated. I describe the mechanics of how this works in Section IV.3.

This procedure has four desirable features; (1) Because the combined residuals are obtained from a model with teacher-by-school fixed effects, the orthogonality condition is satisfied as long as the fixed effects identification assumptions are satisfied; (2) The estimates of the variance of the effects are the maximum likelihood estimates and will not be overstated due to estimation error; (3) This procedure does not mechanically impose the restriction that the mean of the match effects is equal to zero for all teachers (and all schools), but rather apportions variation between the teacher, school, and match effects to minimize mean squared error; (4) Because the match effects and teacher effects are estimated simultaneously, one can disentangle good schools and good teachers from those that are correlated with high quality matches.

\section{IV.3 Intuition for the mechanics of the orthogonal and mixed match effects estimators}

If all teachers were observed in all schools, then one could use a fixed effects estimator to precisely estimate school, teacher and match effects because the orthogonality condition in (13) would be satisfied in the data, there would be enough variation to cleanly identify good matches from good teachers and good schools, and there would be enough observations so that all the estimates would be precise. However, in the real world this is not the case.

Generally, we observe several teachers at the same school so that estimation of school effects is not problematic. However, most teachers are not observed in most schools and many teachers are only observed in a small number of schools, leading to uncertainty in how much of the variation to attribute to teachers or matches. The difference between the orthogonal match fixed effects and the maximum likelihood random match effects is best illustrated by showing an example how these two estimators deal with this uncertainty.

Consider a teacher who is observed with two matches, both of which are positive and large. This could be because (a) the teacher has a very large positive teacher effect, (b) the teacher was very lucky and drew two very large positive matches, or (c) the teacher drew a large teacher effect and two positive match effects (but none of the draws are very large). With only two observed matches for this teacher, there is no way to know for certain which state of the 
world generated the observed data. I detail how each of the estimators deal with uncertainty associated with this scenario to provide intuition for how and why these estimates differ, and why the random maximum likelihood estimates of match effects are desirable.

The orthogonal match fixed effect model mechanically imposes the condition that the mean of the match effects is zero for each teacher. This precludes the possibility of two positive matches ruling out situations (b) and (c). That is, the orthogonal fixed effects model assumes situation (a) and attributes the average of the match effects to teachers. This example illustrates that unless teachers are observed in many schools (where the mean zero match quality assumption may hold for each teacher), the importance of match effects will be understated and that of teacher effects overstated in orthogonal match fixed effects models. Moreover, the example illustrates that the estimated orthogonal teacher and match fixed-effects will be biased.

The random match effects model differs from the orthogonal match effects model in that the estimator distributes the excess variation to both the teacher and match effects in a way that minimizes mean squared error (rather than loading it all on the teacher). The larger/smaller is the estimated variance of the teacher effects relative to the variance of match effects, and the greater/less is its relative precision, the more/less of the excess variation is attributed to the teacher effect. More generally, excess variability is distributed among the effects in proportion to their estimated variance and the precision with which those variances are estimated. The intuition for this is can be illustrated by how it deals with the scenario from above.

Consider again the teacher who is observed with two large positive matches. This could be because of situations (a), (b) or (c) from above. With only two observed matches for this teacher, there is no way to know for certain which state of the world generated the observed data. However, if the variance of teacher effects is large relative to the variance of match effects, then it is more likely that this person drew a very large teacher effect than two very large match effects, and therefore the model will attribute more of the excess variation to the teacher effect. Conversely, if the variance of match effects is large relative to the variance of teacher effects, then it is more likely that this person drew two very large match effects than a very large teacher effect, and therefore the model will attribute more of the excess variation to the match effects. This example illustrates how the mixed effect estimator uses distributional information (obtained from the mobile teachers) to create the Best Linear Unbiased Predictions (BLUPS) of the teacher and match effects (rather than mechanically attributing the excess variation to teachers as in the 
orthogonal match model). The resulting random effect estimates are Empirical Baye's.

Both models identify match effects from the variability in teacher performance across schools (for mobile teachers) but they differ in how they resolve uncertainty about the sources of variability in the data. The orthogonal match fixed effects are the estimates obtained when one ascribes any uncertain variation to the teacher, while the random effect estimates are what one obtains when the model apportions some of the variability to the match and some to the teacher in a way that is most consistent with the distributional assumptions of the model. In principle, both models should yield consistent estimates in large samples, however, in small samples (as is the case in the real world) the fixed-effect estimates will be biased.

\section{IV.4 Estimated Variability of Match Effects}

In Table 5, I present the standard deviations of the raw fixed-effects and the covariancebased and maximum likelihood based estimates of the standard deviations of the teacher, school, and match effects. The units are in standard deviations of student achievement.

The standard deviations of the raw school, teacher, and match fixed effects for math are $0.22,0.35$, and 0.11 , respectively. For reading, the standard deviations of the raw school, teacher and match fixed effects are $0.247,0.356$, and 0.118 , respectively. ${ }^{20}$ While these variances are inflated due to estimation error and idiosyncratic classroom level shocks, if one were to take the estimates at face value, one would conclude that match quality is about half as important as school quality and one-third as important as teacher quality.

The third and fourth columns present the estimates of the true variability of teacher, school, and match effects based on covariance across classrooms to remove estimation error and idiosyncratic classroom level errors. In models that assume that match effect are equal to zero the estimated standard deviation of teacher math quality is 0.1667 , and that of schools is 0.0882 . These estimates are very similar to shrinkage estimates of teacher and school effect in other studies and are consistent with about 40 percent of estimated effectiveness being persistent (Stiager and Rockoff 2010; McCaffrey et al. 2009; Goldhaber and Hansen 2010). The similarity to other studies should assuage concerns that the variability of teacher quality among mobile teachers (for whom these correlations are computed) is different from that for all teachers.

For math, in models that allow for orthogonal match effects, the estimated standard

\footnotetext{
${ }^{20}$ It is important to note that the results are similar but not identical with the inclusion of match fixed effects because in the first stage of the orthogonal match fixed effect estimator match fixed effects are included. Where orthogonal match effects are not estimated, only teacher and school fixed effects are included in the first stage.
} 
deviation of teacher math quality is 0.1498 , and that of schools is unchanged. The estimated standard deviation of match quality in math is 0.0892. These results suggest that about 10 percent of what we typically call a teacher effect in math is actually a match effect, and that the explanatory power of match quality in math is about 60 percent of that of teacher quality. For reading, in models that assume that match effects are equal to zero, the estimated standard deviation of teacher quality in reading is 0.1095 , and that of schools is 0.0504 . In models that allow for orthogonal match effects, the estimated standard deviation of teacher quality in reading falls to 0.0569 . The estimated standard deviation of reading match effects is $0.0878-$ suggesting that about half of what we typically call a teacher effect in reading is actually a match effect, and the explanatory power of match quality in reading is greater than that of teacher quality.

The fifth and sixth and seventh columns presents maximum likelihood estimates. The mixed effects estimator suggests that with no match or classroom effects, the standard deviations of teacher quality for math and reading are 0.19 and 0.11 , respectively, and that the standard deviations of school quality for math and reading are 0.106 and 0.0926 , respectively. These estimates are similar to the covariance based estimates, providing confidence in the variability estimates, and underscoring the importance accounting for estimation error. In the mixed effect model that allows for match effects only (that can be correlated with school or teacher effects) the standard deviation of school effects falls to 0.099 for math and to 0.0655 for reading suggesting that match quality can "explain away" about 7 and 30 percent of school effects in math and reading, respectively. Where match effects are included, the standard deviation of teacher effects falls to 0.141 for math and 0.0837 in reading - suggesting that match quality "explains away" about 25 percent of teacher effects in both subjects. Because one may confound match effects with classroom effects in small samples, the estimated standard deviations of match effects of 0.13 for math and 0.077 for reading are likely inflated. In the maximum likelihood model that accounts for classroom level effects, the standard deviation of match effects is 0.0953 for math and 0.0597 for reading. As such, match effects have about two-thirds of the explanatory power of teacher effects and are economically important.

One may worry that these calculations may overstate the relative importance of match effects because the variation in teacher quality is measured within schools. If there is substantial sorting of teachers across schools the variability in teacher quality within schools may understate the importance of teachers. To assess the degree to which this might be true I compare the 
standard deviation of teacher effects in models that do and do not include school effects. Starting with the naïve model, the standard deviation of estimated raw teacher fixed effects without the inclusion of school or match fixed effects is 0.321 and 0.327 for math and reading, respectively. This is almost identical to the variability within schools. Similarly, in the maximum likelihood model that does not include school effects the estimated standard deviations are 0.211 and 0.1294 for math and reading, respectively. Again, this is almost identical to the estimated variability within schools (without match effects). Furthermore, this is consistent with Rivkin, Hanushek, and Kain (2005) and Aaronson, Barrow, and Sander (2007), who show that the within-school variation in value added is as large as between-school variation, suggesting the estimated variability of teacher quality based on within school comparisons is not understated so that the relative importance of match effects is likely not overstated.

\section{Does Match Quality Predict Teacher Mobility?}

The remaining empirical predictions from the theoretical framework in section I.5 were that (a) match specific quality should be negatively associated with switching, (b) match specific quality should be largely unrelated to exiting the profession, (c) general teacher quality should be negatively correlated with exiting the profession, and (d) general teacher quality should be unrelated to switching within teaching. To test these empirical predictions, I merge in both the preferred estimated random estimates (the BLUPs) and the estimated orthogonal fixed-effects with teacher-level mobility data, and see whether teacher mobility (switching schools or exiting the data) is associated with teacher quality (occupation-specific ability) and match quality (firmspecific ability) at her current school. Specifically I estimate (15) below by logistic regression.

$$
\operatorname{Pr}\left(Y_{j s y+1}\right)=\frac{1}{1+e^{-\left(\alpha_{1} X_{X_{j y}}+\alpha_{2} X_{s_{y}}+\pi_{1} \bar{\theta}_{j}+\pi_{2} \bar{\theta}_{j s}\right)}} .
$$

$Y_{j s y+1}$ is an indicator variable equal to 1 if the teacher switches from her current school in year $y$ (i.e. teacher $j$ at school $s$ at time $y$ is not in school $s$ at time $y+1$ but is in another school teaching any grade in the NC public school system in year $y+1$ ) or exits the NC public school system entirely, $X_{j y}$ is a set of time varying teacher level covariates, $X_{s y}$ is a set of time varying school level covariates, $\theta_{j}$ and $\theta_{j s}$ are standardized estimated teacher and match effects.

To allow for comparisons conditional on the teacher identity or school identity, and assuage concerns that the relationships are due to high mobility teachers or schools having bad 
matches on average, I also estimate conditional logistic regressions that condition on either the teacher or the school. Finally, while not tractable in a non-linear model, to allow both unobserved teacher and school level heterogeneity, I estimate a linear probability model with both teacher and school fixed effects. Specifically I estimate (16) below by OLS.

$$
\text { Switch }_{j s y+1}=\alpha_{1} X_{j y}+\alpha_{2} X_{s y}+\pi_{3} \bar{\theta}_{j s}+\pi_{j}+\pi_{s}+\varepsilon_{j s y} \quad .
$$

In (16), $\pi_{s}$ and $\pi_{j}$ are teacher and school fixed effects, respectively, and $\varepsilon_{j s y}$ is the idiosyncratic error term. This model tests for whether a given mobile teacher was more or less likely to remain in her current school where the estimated match quality is higher, taking into account that certain schools may have high/low mobility and high/low match quality on average. Results of these models are presented in Table 6. For the logistic regressions I present the odds ratios (less than one means less likely to exit or switch and more than 1 means more likely to exit or switch) and the $p$-value associated with the null hypothesis that the estimates odds ratio is equal to 1 (i.e. no change in likelihood). For the linear probability models I present the marginal effects and compute the implied odds ratio based on the mean of the dependent variable for comparison. I only present results for math, however they are similar for reading.

The results in columns 1 and 2 are consistent with the theory. That is, increasing teacher quality (a transferable skill within teaching) by $1 \sigma$ decreases the likelihood of exiting the teaching profession by 12 percent but is unrelated to switching schools. This is consistent with teachers leaving the profession for other professions with which they may have a better "match". ${ }^{21}$ Also, while increasing match quality (a school-specific skill) by $1 \sigma$ decreases the likelihood of exiting the profession by only 6 percent, it decreases the likelihood of switching by 33 percent. While the previous literature has not made the distinction between teacher effectiveness due to school-specific versus general skills, these results show that effectiveness due to school-specific skills is associated with staying with the school, while effectiveness due to general teaching ability is associated with staying in the profession.

Columns 3 and 4 include school and teacher characteristics and this has little effect on the relationships between match and teacher quality on mobility. The observable teacher and school characteristics predict mobility as one would expect; Higher salaries are associated with both decreased switching and decreased exit (with stronger effects on exit), the percentage of black

\footnotetext{
${ }^{21}$ These finding are consistent with (Loeb, Kalogrides and Béteille 2011) who find that more effective schools are able to attract and hire more effective teachers from other schools when vacancies arise.
} 
students at the school is associated with increased switching and decreased exit (with larger effects on switching), and higher math achievement at the school is associated with less switching and exit. While exiting the profession increases monotonically with experience, switching schools decreases monotonically with experience. This is consistent with teachers being more likely to retire as they age and with teachers settling in on a good match as they age. Higher licensure scores and having an advanced degree (indicative of general cognitive skill that may be transferable to other occupations and schools) is associated increased exit and switching. Having regular licensure (which indicates attachment to the profession and is a marketable trait for other schools) is associated with 53 percent less exit but 67 percent more switching.

These general relationships persist in models that condition on the individual teacher (columns 5 and 6) or those that condition on the school (columns 7 and 8). The linear models that condition on both teacher and school (columns 9 and 10) show that increasing match quality by $1 \sigma$ has no statistically significant effect on exiting the profession, but is associated with being 2.7 percentage points ( $p$-value $=0.000$ ) less likely to switch schools (an implied 66 percent reduction). This is what one should observe if the estimated match effects capture something school-specific that is not transferable across schools but is valuable in schools. To assuage worries that these patterns are driven by the particulars of the random effect estimates, columns 11 and 12 show the preferred mobility regressions replacing the random match effects with the estimated orthogonal fixed match effects. The results, though less precise, are similar.

In sum, consistent with classic models of match quality and mobility, teachers (workers) are less likely to leave their current school when match quality is high and no more likely to leave the profession. In contrast, teachers with high general teaching ability are more likely to stay in the profession and no more likely to switch schools. The patterns of exit and switching are consistent with prior findings that those teachers who exit from inner city schools are those who were the least effective and suggest that the patterns of exit and switching are due to teacher-school and teacher-profession match quality and are consistent with standard models of job search. Importantly, these relationships persist conditional on teacher salary so that match quality affects teacher mobility for reasons unrelated to pay. This suggests that non-pecuniary job aspects (such as working conditions, job satisfaction, or in-kind benefits) that are correlated with match effects exert an important effect on employee mobility decisions. 


\section{VI.1 The Correlates of Match Quality}

While match quality is a teacher-school concept, if teachers leave bad matches and are more likely to have outside options if they are more desirable to other schools then there are certain patterns that one might expect to see in the data. One might expect that teachers with more years of experience (who have been able to shop for a good match) will on average have better matches, characteristics that make a teacher more employable should be associated with better matches (more able to be employed at a school with high match quality), and larger schools and schools in more densely populated areas should have better matches (because larger markets and school allow for greater specialization increasing the likelihood of a good match).

To test for such patterns, I regress the standard normalized match random effects on the observable teacher and school characteristics included in equation (8). ${ }^{22}$ Table 7 presents the observable correlates of match quality. Columns 1 and 2 show that teachers with more years of experience have higher match quality in both math and reading. Note that teacher experience is already accounted for when estimating match effects. To assess whether this relationship reflects a composition effect or teachers moving to schools with higher match quality over time, I estimate this relationship with the inclusion of teacher fixed-effects (columns 3 and 4). This within-teacher estimate documents the relationship between match quality and experience among those mobile teachers who switch schools over time. While the within-teacher relationship is smaller in magnitude, there is a clear positive monotonic relationship between experience and match quality within teachers. This is consistent with the pre and post comparisons depicted in Figure 1 and the mobility patterns documented in Table 6, and is indicative of teachers moving from schools with lower quality matches and remaining in schools with higher quality matches.

Columns 1 and 2 show that certified teachers, teachers with regular licensure, and teachers with higher scores on their license exams have better matches in both math and reading. Also, white teachers have higher match quality in math than other teachers. These results imply that at least part of the reason more experienced teachers, teachers who have a regular license, certified teachers, and white teachers may be associated with better student outcomes is due to the fact that such teachers have traits that are desirable to employers so that they are better able to search for higher match quality (as opposed to these traits being productive per se).

Relative to schools in large cities, average match quality is lower in both math and

\footnotetext{
${ }^{22}$ These are simple regression of the form $\bar{\theta}_{j s}=\rho_{1} X_{j}+\rho_{2} X_{s}+\varepsilon_{j s y}$.
} 
reading in small towns, mid-sized cities, and rural areas. Match quality is positively associated with school size for both math and reading (possibly due to greater scope for classroom specialization). These patterns are consistent with the job search model such that match quality is higher in geographic areas with thicker markets and school with greater scope for specialization. Columns 5 through 8 show the same models with the raw fixed effects. While patterns are less pronounced and less precise (as one would expect), the patterns are largely similar.

\section{VI.2 Do certain kinds of teachers perform better at certain kinds of schools?}

To better understand these match effects, it is helpful to assess what kind of teacherschool combinations are associated with better or worse outcomes. In principle, one could run a value-added model with both teacher and school fixed effects while including each teacher variable interacted with each school variable. Because this would results in a regression with hundreds of variables, this approach is impractical. As such, I employ a factor analytical approach that aggregates all the variables into a few manageable number of factors that categorize teachers and schools into types (Appendix Table 1). I then interact the teacher and schools factors to see if certain teacher types have better outcomes with certain school types. ${ }^{23}$

To create factors for teachers, I included teachers value-added in math and reading, their certification status, whether they were fully licensed, their average score on licensure exams, the 75th percentile of the SAT distribution of their college, years of teaching experience and possessing an advanced degree. These variables loaded onto three factors: (1) effective teachers, (2) teachers with high cognitive ability, and (3) teachers with strong paper credentials. To create factors for school characteristics, I included student demographics, student achievement levels, enrollment and urbanicity variables. The school variables loaded onto three factors: (1) highachieving suburban schools, (2) mid achievement, rural, white schools, and (3) low-achieving, inner city schools. I also take advantage of a teacher workplace conditions survey that can be linked to schools but not teachers. The survey contains 23 questions common across all survey years. Teacher are asked to state their level of agreement with statements such as "Teachers have time to collaborate with colleagues" and "Teachers are held to high standards". These survey responses loaded onto four factors; (1) strong leadership and high-standards, (2) well-resourced, (3) teachers have time, and (4) emphasis on professional development.

\footnotetext{
${ }^{23}$ This approach has been used by economists to study teaching practices associated with between student outcomes (Lavy 2011) and the relationship between teacher traits and student outcomes (Rockoff, Jacob, et al. 2011).
} 
To see which teacher-school combinations are associated with better/worse student outcomes I estimate a value-added model like (16) below by OLS, where $Z_{j}$ and $Z_{s}$ are teacher and school types (factors), respectively.

$$
T_{i j s y}=\gamma T_{i y-1}+X_{i j s y} \alpha+\delta\left(Z_{j} \cdot Z_{s}\right)+\theta_{j}+\theta_{s}+\eta_{i j s y}
$$

Results are presented in Table 8. Because teacher peer characteristics are also an important part of the school environment, I use the mean of the teacher types as a school level characteristic.

Table 8 reveals a few patterns that are robust across subjects. Effective teachers (high value-added teachers) perform relatively better at schools with highly credentialed teachers, better at schools with an emphasis on professional development and relatively worse at high achievement suburban schools. In contrast, teachers with strong credentials (experienced, licensed, and have a masters degree) perform relatively worse in schools with more cognitive type teachers (teacher from selective colleges with high scores on their exams), better in inner city schools and worse in schools with an emphasis on professional development. Finally, high cognitive teachers perform worse in schools with strong leadership and schools with an emphasis on professional development. Because researchers have found racial match effects (Dee 2004, 2005; Ouazad 2008) I test for such effects at the school level (appendix Table A2). Once teacher and school effects are included, there is evidence that white teachers perform relatively better at rural schools with high shares of white students but little evidence that black teachers perform any better or worse at schools with larger shares of white or black teacher or students.

While these correlations should be interpreted with caution, the estimated effects are sufficiently large that there could be non-trivial gains to optimally matching teachers to schools. For example, teachers who are 1sd above the mean in effectiveness would improve test scores by $0.05 \sigma$ more at schools that score $1 \sigma$ higher on their emphasis on professional development. Also, teachers who are $1 \sigma$ above the mean in effectiveness would improve test scores by $0.03 \sigma$ less at a school that is more suburban, affluent, and high-achieving.

\section{Conclusions}

I document that teachers perform better in the classroom after a move to another school than before the move. I present a variety of empirical tests showing that this cannot be explained by teachers moving to higher-achieving schools, endogenous teacher movement, or student selection. I then provide the first direct estimates of match effects using measures of worker 
output (as opposed to inferring them from wages) and find that match quality an important determinant of student achievement. The variability of match effects are about two-thirds as large as teacher effects and about one quarter of what we typically interpret as a teacher quality effect is a match quality effect that is not portable across schools. Even though there is no direct relationship between productivity and wages for teachers, a variety of empirical patters are consistent with canonical model of job search. Specifically, teachers with high school-specific quality are less likely to switch from such schools but no more likely to exit the profession, while teachers with high general teaching quality are no more likely to switch schools but less likely to exit the profession. Also, match quality increases and school switching decreases monotonically with experience - consistent with workers switching jobs until they find a productive match.

These findings validate previous theoretical and empirical work on worker mobility using wages to infer match quality. Also, that match quality predicts mobility in a context where there is no relationship between wages and productivity suggests that workers may value highproductivity matches for reasons other than monetary compensation. Both these finding are important contributions to the literature on worker mobility. These finding are also important for the education literature and have important policy implications. Certain kinds of teacher school combinations are associated with better outcomes such that a teacher placement policy that maximized match quality could lead to meaningfully improved student outcomes. The finding also indicate that policy-makers should be cautious about identifying strong teachers in one school and moving them to another. Moreover, because match and teacher quality are often confounded, policy simulations based on teacher quality estimates that do not account for match quality could be inaccurate. Fortunately, the results indicate that teachers tend to leave schools at which they are poorly matched, so that teacher turnover (which is generally considered a bad thing) may in fact move us closer to an optimal allocation of teacher to schools. 


\section{References}

Aaronson, Daniel, Lisa Barrow, and William Sander. "Teachers and Student Achievement in the Chicago Public High Schools." Journal of Labor Economics 25 (2007): 95-135.

Abowd, J. M., F. Kramarz, and D. N. Margolis. "High wage workers and high wage firms." Econometrica 67, no. 2 (1999): 251-33.

Abowd, J. M., F. Kramarz, P. Lengermann, and S. Perez-Duarte. "Are good workers employed by good firms? A test of a simple assortative matching model for France and the United States." mimeo, 2004.

Abowd, John M., Robert H. Creecy, and Francis Kramarz. "Computing Person and Firm Effects Using Linked Longitudinal Employer-Employee Data." U.S. Census Bureau Technical Paper TP-2002-06, 2002.

Akerlof, George A., and Rachel E. Kranton. "Identity and the Economics of Organizations." Journal of Economic Perspectives 19, no. 1 (2005): 9-32.

Altonji, J. G., and R. A. Shakotko. "Do wages rise with job seniority?" Review of Economic Studies 54, no. 3 (1987): 437-459.

Anthony, Emily, and Dan Goldhaber. "Can teacher quality be effectively assessed? National board certification as a signal of effective teaching." Review of Economics and Statistics 89, no. 1 (2007): 134-50.

Bartel, A. P., and G. J. Borjas. "Wage growth and job turnover: An empirical analysis." In Studies in Labor Markets, 65-90. Chicago: NBER, 1981.

Brewer, Dominic J., and Dan D. Goldhaber. "Does teacher certification matter? High school teacher certification status and student achievement." Educational Evaluation and Policy Analysis 22, no. 2 (2000): 129-45.

Brewer, Dominic J., and Ronald G. Ehrenberg. "Do school and teacher characteristics matter? Evidence from high school and beyond." Economics of Education Review 13, no. 1 (1994): 1-17.

Brown, Gordon D.A., Jonathan Gardner, and Andrew Oswald. "Does Wage Rank Affect Employees' Wellbeing?" University of Warwick Working Paper, 2006.

Burdett, Kenneth. "A Theory of Employee Job Search and Quit Rates." American Economic Review 68 (1978): 212-220.

Clotfelter, Charles T., Helen F. Ladd, and Jacob L. Vigdor. "How and why do teacher credentials matter for student achievement?" NBER Working Paper 12828, 2007.

Clotfelter, Charles T., Helen F. Ladd, and Jacob L. Vigdor. "Who teaches whom? Race and the distribution of novice teachers." Economics of Education Review 24, no. 2 (2006): 377-92.

Dee, Thomas S. "A teacher like me: Does race, ethnicity, or gender matter?" American Economic Review (95) 2 (2005): 158-165.

Dee, Thomas S. "Teachers, race, and student achievement in a randomized experiment." Review of Economics and Statistics 86, no. 1 (2004): 195-210.

Di Tella, R., R . J. MacCulloch, and J. A. Oswald. "Preferences Over Inflation and Unemployment: Evidence from Surveys of Happiness." American Economic Review 91, no. 1 (2001): 335-341.

Duncan, Greg J. "Earnings Functions and Nonpecuniary Benefits." The Journal of Human Resources 11, no. 4 (1976): 462-483.

Hanushek, Eric A. "Assessing the effects of school resources on student performance: An update." Educational Evaluation and Policy Analysis 19, no. 2 (1997): 141-64.

Hanushek, Eric A., John F. Kain, Daniel M. O'Brien, and Steven Rivkin. "The Market for Teacher Quality." NBER working paper 11154, 2005.

Hanushek, Eric A., John Kain, and Steven Rivkin. "Why Public Schools Lose Teachers." Journal of Human Resources 39, no. 2 (2004): 326-354.

Jackson, C. Kirabo. "School Competition and Teacher Quality: Evidence from Charter School Entry in North Carolina." Cornell university mimeo, 2010.

Jackson, C. Kirabo. "Student Demographics, Teacher Sorting, and Teacher Qualty: Evidence From the End of School Desegregation." Journal of Labor Economics 27, no. 2 (2009): 213-256. 
Jackson, C. Kirabo, and Elias Bruegmann. "Teaching Students and Teaching Each Other: The Importance of Peer Learning for Teachers." American Economic Journal: Applied Economics 1, no. 4 (2009): 85108.

Jacob, Brian A., and Lars Lefgren. "Can Principals Identify Effective Teachers? Evidence on Subjective Performance Evaluation in Education." Journal of Labor Economics 26, no. 1 (2008): 101-36.

Johnson, W. "A Theory of Job Shopping." The Quarterly Journal of Economics 92 (1978): 261-277.

Jovanovic, Boyan. "Job Matching and the Theory of Turnover." Journal of Political Econoomy, no. 87 (1979): 972-990.

Kane, Thomas, and Douglas Staiger. "Estimating Teacher Impacts on Student Achievement: An Experimental Evaluation." NBER working paper 14607, 2008.

Korpi, T. "Is Well-Being Related to Employment Status? Unemployment, Labor Market Policies and Subjective Well-Being among Swedish Youth." Labour Economics 4, no. 2 (1997): 125-147.

Lankford, Hamilton, Susanna Loeb, and James Wyckoff. "Teacher sorting and the plight of urban schools: A descriptive analysis." Educational Evaluation and Policy Analysis 24, no. 1 (2002): 3762.

Lavy, Victor. "What Makes an Effective Teacher? Quasi-Experimental Evidence." working paper Hebrew University, 2011.

Loeb, Susanna, Demetra. Kalogrides, and Tara Béteille. "Effecitve Schools: Teacher Hiring, Assignment, Development, and Retention." working paper, 2011.

Mincer, Jacob, and Boyan Jovanovic. "Labor Mobility and Wages." In Studies in Labor Markets, 21-64. NBER, 1981.

Mortensen, Dale. "Specific Capital and Labor Turnover." The Bell Journal of Economics 9 (1998): 572586.

Nagypal, E. "Learning by doing vs. learning about match quality: Can we tell them apart?" Review of Economic Studies 74 (2007): 537-566.

Neal, Derek. "The complexity of job mobility among young men." Journal of Labor Economics 17 (1999): 237-261.

Ost, Ben. "How Do Teachers Improve? The Relative Importance of Specific and General Human Capital." Cornell mimeo, 2009.

Ouazad, Amine. "Assessed by a teacher like me: Race, gender and subjective evaluations." CEE Discussion Paper 0098, 2008.

Papay, J. P., and M Kraft. "Do Teachers Continue to Improve with Experience? Evidence of Long-Term Career Growth in the Teacher Labor Market." working paper, 2010.

Rivkin, Steven G., Eric A. Hanushek, and John F. Kain. "Teachers, Schools, and Academic Achievement." Econometrica 73, no. 2 (2005): 417-458.

Rockoff, Jonah E. "The Impact of Individual Teachers on Student Achievement: Evidence from Panel Data." American Economic Review 94, no. 2 (2004): 247-52.

Rockoff, Jonah E., Brian A. Jacob, Thomas J. Kane, and Douglas O. Staiger. "Can You Recognize an Effective Teacher When You Recruit One?" Education Finance and Policy 6, no. 1 (2011): 43-74.

Rothstein, Jesse. "Teacher Quality in Educational Production: Tracking, Decay, and Student Achievement." Quarterly Journal of Economics, 2010.

Sass, Timothy, and Li Feng. "Teacher Quality and Teacher Mobility." Florida State University working paper, 2008.

Topel, R. H., and M. P. Ward. "Job mobility and the careers of young men." Quarterly Journal of Economics 107, no. 2 (1992): 439-479.

Winkelmann, L., and R. Winkelmann. "Why Are the Unemployed So Unhappy?" Economica 65, no. 257 (1998): 1-15.

Woodcock, Simon D. "Match Effects." Simon Fraser University mimeo, 2008. 


\section{Tables and Figures}

Table 1: Summary Statistics

\begin{tabular}{lccc}
\hline \multicolumn{1}{c}{ Variable } & Observations & Mean & Standard Deviation \\
\hline Unit of Observation: Student-Year & & & \\
Math Scores & 1361473 & 0.033 & 0.984 \\
Reading Scores & 1355313 & 0.022 & 0.984 \\
Change in Math Score & 1258483 & 0.006 & 0.583 \\
Change in Reading Score & 1250179 & 0.001 & 0.613 \\
Black & 1372098 & 0.295 & 0.456 \\
White & 1372098 & 0.621 & 0.485 \\
Female & 1372098 & 0.493 & 0.500 \\
Parent Ed.: No HS Degree & 1372098 & 0.107 & 0.309 \\
Parent Ed.: HS Degree & 1372098 & 0.428 & 0.495 \\
Parent Ed.: Some College & 1372098 & 0.315 & 0.464 \\
Parent Ed.: College Degree & 1372098 & 0.143 & 0.350 \\
Same Race & 1372098 & 0.649 & 0.477 \\
Same Sex & 1372098 & 0.496 & 0.500 \\
Class Size & 1372098 & 23.054 & 4.053 \\
& & & \\
Unit of Observation: Teacher-Year & & & 9.949 \\
Experience & 91243 & 12.798 & 0.242 \\
Experience 0 & 92511 & 0.063 & 0.371 \\
Experience 1 to 3 & 92511 & 0.165 & 0.421 \\
Experience 4 to 9 & 92511 & 0.230 & 0.481 \\
Experience 10 to 24 & 92511 & 0.365 & 0.371 \\
Experience 25+ & 92511 & 0.164 & 0.812 \\
Teacher Exam Score & & & 0.398 \\
Advanced Degree & 92511 & -0.012 & 0.194 \\
Regular Licensure & 92511 & 0.197 & \\
Certified & 92511 & 0.670 & 0.039 \\
\hline
\end{tabular}

Notes: The few teachers with more than 50 years of experience are coded as having 50 years of experience. 
Table 2: Relationship Between School Switching and Teacher Characteristics

\begin{tabular}{lcccc} 
& \multicolumn{2}{c}{1} & 2 & \multicolumn{2}{c}{3} & 4 \\
\cline { 2 - 5 } Experience: 1 to 3 & \multicolumn{2}{c}{ Switch Schools in 1 year } & \multicolumn{2}{c}{ Exit Teaching in 1 year } \\
\cline { 2 - 5 } & -0.002 & -0.003 & 0.015 & 0.026 \\
Experience: 4 to 9 & {$[0.005]$} & {$[0.005]$} & {$[0.009]^{+}$} & {$[0.009]^{* *}$} \\
& -0.006 & -0.007 & -0.023 & -0.001 \\
Experience: 10 to 24 & {$[0.005]$} & {$[0.006]$} & {$[0.009]^{*}$} & {$[0.009]$} \\
& -0.015 & -0.012 & -0.102 & -0.068 \\
Experience: 25+ & {$[0.005]^{* *}$} & {$[0.005]^{*}$} & {$[0.009]^{* *}$} & {$[0.009]^{* *}$} \\
& -0.057 & -0.054 & -0.064 & -0.029 \\
Licensure Score & {$[0.006]^{* *}$} & {$[0.006]^{* *}$} & {$[0.009]^{* *}$} & {$[0.010]^{* *}$} \\
& -0.007 & -0.003 & -0.004 & 0.001 \\
Advanced Degree & {$[0.001]^{* *}$} & {$[0.002]^{*}$} & {$[0.003]$} & {$[0.003]$} \\
& 0.003 & 0.003 & 0.031 & 0.031 \\
Regular License & {$[0.003]$} & {$[0.003]$} & {$[0.006]^{* *}$} & {$[0.006]^{* *}$} \\
& 0.034 & 0.045 & -0.19 & -0.178 \\
Year FX & {$[0.005]^{* *}$} & {$[0.005]^{* *}$} & {$[0.008]^{* *}$} & {$[0.008]^{* *}$} \\
School FX & YES & YES & YES & YES \\
\hline Observations & NO & YES & NO & YES \\
R-squared & 89856 & 89856 & 75303 & 75303 \\
\hline Robust Stand & 0.17 & 0.2 & 0.03 & 0.08 \\
\hline
\end{tabular}

Robust standard errors in brackets are adjusted for clustering at the teacher level. + significant at $10 \%$; * significant at $5 \%$; ** significant at $1 \%$ 
Table 3: Comparing sending and Receiving Schools (By teacher type)

\begin{tabular}{|c|c|c|c|c|c|c|c|}
\hline & 1 & 2 & 3 & 4 & 5 & 6 & 7 \\
\hline \multicolumn{8}{|c|}{ Difference in characteristics between receiving and sending school } \\
\hline & All & White & non-white & Hi Score & Low score & $>5$ years exp & $<10$ years \\
\hline \multirow[t]{2}{*}{ Reading scores (class) } & -0.054 & -0.06 & -0.028 & -0.076 & -0.036 & -0.111 & -0.025 \\
\hline & {$[0.009]^{* *}$} & {$[0.010]^{* *}$} & [0.023] & {$[0.018]^{* *}$} & {$[0.018]+$} & {$[0.024]^{* *}$} & {$[0.013]^{*}$} \\
\hline \multirow[t]{2}{*}{ Reading scores (school) } & -0.023 & -0.03 & 0.013 & -0.034 & -0.005 & -0.061 & 0.001 \\
\hline & {$[0.005]^{* *}$} & {$[0.005]^{* *}$} & [0.013] & {$[0.010]^{* *}$} & [0.010] & {$[0.014]^{* *}$} & {$[0.006]$} \\
\hline \multirow[t]{2}{*}{ Mean class size } & 0.236 & 0.184 & 0.503 & 0.133 & 0.356 & -0.008 & 0.366 \\
\hline & {$[0.052]^{* *}$} & {$[0.055]^{* *}$} & {$[0.141]^{* *}$} & {$[0.106]$} & {$[0.106]^{* *}$} & [0.137] & {$[0.072]^{* *}$} \\
\hline \multirow[t]{2}{*}{ \% Non-white teachers } & 0.015 & 0.021 & -0.015 & 0.019 & -0.001 & 0.028 & 0.003 \\
\hline & {$[0.004]^{* *}$} & {$[0.005]^{* *}$} & [0.010] & {$[0.009]^{*}$} & [0.009] & {$[0.013]^{*}$} & {$[0.006]$} \\
\hline \multirow[t]{2}{*}{ Log of Salary } & -0.073 & -0.073 & -0.068 & -0.075 & -0.07 & -0.072 & -0.052 \\
\hline & {$[0.002]^{* *}$} & {$[0.002]^{* *}$} & {$[0.006]^{* *}$} & {$[0.003]^{* *}$} & {$[0.004]^{* *}$} & {$[0.005]^{* *}$} & {$[0.002]^{* *}$} \\
\hline \multirow[t]{2}{*}{ Percent Free lunch } & 0.038 & 0.039 & 0.034 & 0.038 & 0.039 & 0.046 & 0.035 \\
\hline & {$[0.003]^{* *}$} & {$[0.003]^{* *}$} & {$[0.010]^{* *}$} & {$[0.006]^{* *}$} & {$[0.007]^{* *}$} & {$[0.009]^{* *}$} & {$[0.004]^{* *}$} \\
\hline \multirow[t]{2}{*}{ Percent Black } & 0.025 & 0.029 & 0.003 & 0.028 & 0.011 & 0.036 & 0.016 \\
\hline & {$[0.003]^{* *}$} & {$[0.003]^{* *}$} & [0.007] & {$[0.005]^{* *}$} & {$[0.005]^{*}$} & {$[0.009]^{* *}$} & {$[0.003]^{* *}$} \\
\hline \multirow[t]{2}{*}{ Log of Enrolment } & -0.013 & -0.016 & -0.001 & -0.01 & -0.008 & -0.019 & -0.001 \\
\hline & {$[0.006]^{*}$} & {$[0.006]^{*}$} & [0.014] & [0.012] & {$[0.011]$} & {$[0.016]$} & {$[0.007]$} \\
\hline \multirow[t]{2}{*}{ Large City } & -0.002 & 0.001 & -0.012 & -0.002 & -0.008 & 0.002 & 0 \\
\hline & {$[0.003]$} & {$[0.003]$} & {$[0.007]+$} & {$[0.005]$} & {$[0.004]+$} & {$[0.007]$} & {$[0.003]$} \\
\hline \multirow[t]{2}{*}{ Mid-sized city } & 0.015 & 0.02 & -0.011 & 0.022 & -0.002 & 0.006 & 0.01 \\
\hline & {$[0.005]^{* *}$} & {$[0.005]^{* *}$} & [0.012] & {$[0.011]^{*}$} & {$[0.010]$} & {$[0.016]$} & {$[0.006]+$} \\
\hline \multirow[t]{2}{*}{ Urban Fringe } & 0.003 & 0 & 0.019 & -0.003 & 0.025 & -0.011 & 0.015 \\
\hline & {$[0.006]$} & {$[0.006]$} & [0.012] & [0.012] & {$[0.011]^{*}$} & {$[0.017]$} & {$[0.007]^{*}$} \\
\hline \multirow[t]{2}{*}{ Town } & 0.02 & 0.02 & 0.014 & 0.02 & 0.022 & 0.031 & 0.01 \\
\hline & {$[0.004]^{* *}$} & {$[0.005]^{* *}$} & {$[0.010]$} & {$[0.008]^{*}$} & {$[0.009]^{*}$} & {$[0.014]^{*}$} & {$[0.005]^{*}$} \\
\hline \multirow[t]{2}{*}{ Rural Area } & -0.036 & -0.041 & -0.01 & -0.037 & -0.036 & -0.026 & -0.035 \\
\hline & {$[0.006]^{* *}$} & {$[0.007]^{* *}$} & [0.013] & {$[0.013]^{* *}$} & {$[0.012]^{* *}$} & [0.019] & {$[0.008]^{* *}$} \\
\hline
\end{tabular}

Each coefficient represents a separate regression of each covariate on an "post switch" indicator variable. Robust standard errors in brackets are adjusted for clustering at the teacher level.

+ significant at $10 \%$; * significant at $5 \%$; ** significant at $1 \%$. 
Table 4: Teacher Effectiveness Before and After a Move

\begin{tabular}{|c|c|c|c|c|c|c|c|c|}
\hline & 1 & 2 & 3 & 4 & 5 & 6 & 7 & 8 \\
\hline & \multicolumn{4}{|c|}{ Math } & \multicolumn{4}{|c|}{ Reading } \\
\hline & Growth & Score & Score & Score & Growth & Score & Score & Score \\
\hline \multirow[t]{2}{*}{10 Years before move } & -0.059 & -0.049 & -0.048 & -0.013 & -0.069 & -0.053 & -0.059 & -0.042 \\
\hline & {$[0.027] *$} & {$[0.025]+$} & {$[0.025]^{*}$} & [0.023] & {$[0.027] *$} & {$[0.026]^{*}$} & {$[0.026]^{*}$} & {$[0.024]+$} \\
\hline \multirow[t]{2}{*}{9 Years before move } & -0.046 & -0.041 & -0.045 & 0 & -0.046 & -0.033 & -0.035 & -0.034 \\
\hline & {$[0.019]^{*}$} & {$[0.018]^{*}$} & {$[0.018]^{*}$} & [0.017] & {$[0.015]^{* *}$} & {$[0.014] *$} & {$[0.014]^{*}$} & {$[0.014]^{*}$} \\
\hline \multirow[t]{2}{*}{8 Years before move } & -0.011 & -0.008 & -0.017 & -0.011 & -0.01 & 0 & -0.006 & -0.013 \\
\hline & {$[0.016]$} & [0.015] & [0.015] & {$[0.014]$} & {$[0.012]$} & {$[0.011]$} & {$[0.011]$} & {$[0.011]$} \\
\hline \multirow[t]{2}{*}{7 Years before move } & -0.008 & -0.002 & -0.009 & 0.009 & -0.011 & 0.002 & -0.002 & -0.005 \\
\hline & [0.013] & [0.012] & [0.012] & [0.012] & {$[0.010]$} & {$[0.010]$} & [0.010] & {$[0.010]$} \\
\hline \multirow[t]{2}{*}{6 Years before move } & -0.005 & -0.002 & -0.01 & 0.001 & -0.016 & -0.004 & -0.012 & -0.013 \\
\hline & [0.012] & [0.011] & {$[0.011]$} & [0.010] & {$[0.009]+$} & {$[0.008]$} & [0.008] & [0.009] \\
\hline \multirow[t]{2}{*}{5 Years before move } & 0.002 & 0.004 & -0.002 & 0.01 & -0.014 & -0.003 & -0.009 & -0.008 \\
\hline & {$[0.010]$} & [0.009] & [0.009] & [0.009] & {$[0.008]+$} & {$[0.007]$} & [0.007] & {$[0.007]$} \\
\hline \multirow[t]{2}{*}{4 Years before move } & -0.003 & 0.001 & -0.006 & 0.002 & -0.008 & 0 & -0.007 & -0.011 \\
\hline & [0.009] & [0.008] & [0.008] & {$[0.007]$} & {$[0.007]$} & {$[0.007]$} & {$[0.007]$} & {$[0.006]+$} \\
\hline \multirow[t]{2}{*}{3 Years before move } & -0.007 & -0.003 & -0.007 & 0.002 & -0.005 & 0.003 & -0.002 & -0.007 \\
\hline & {$[0.007]$} & [0.007] & {$[0.007]$} & {$[0.006]$} & {$[0.006]$} & {$[0.006]$} & {$[0.006]$} & {$[0.006]$} \\
\hline \multirow[t]{2}{*}{2 Years before move } & -0.002 & 0.001 & 0 & 0.002 & -0.001 & 0.005 & 0.002 & -0.003 \\
\hline & {$[0.006]$} & {$[0.006]$} & {$[0.006]$} & [0.006] & {$[0.006]$} & {$[0.005]$} & [0.005] & {$[0.005]$} \\
\hline \multirow[t]{2}{*}{ Year of move ( 0 ) } & 0.013 & 0.016 & 0.009 & 0.006 & 0.006 & 0.01 & 0.001 & -0.001 \\
\hline & {$[0.006]^{*}$} & {$[0.005]^{* *}$} & {$[0.006]$} & [0.006] & [0.005] & {$[0.005]^{*}$} & [0.005] & {$[0.005]$} \\
\hline \multirow[t]{2}{*}{1 Year after move } & 0.028 & 0.032 & 0.026 & 0.023 & 0.017 & 0.02 & 0.011 & 0.009 \\
\hline & {$[0.007]^{* *}$} & {$[0.006]^{* *}$} & {$[0.006]^{* *}$} & {$[0.006]^{* *}$} & {$[0.005]^{* *}$} & {$[0.005]^{* *}$} & {$[0.005]^{*}$} & {$[0.005]+$} \\
\hline \multirow[t]{2}{*}{2 Years after move } & 0.034 & 0.039 & 0.033 & 0.027 & 0.02 & 0.024 & 0.014 & 0.011 \\
\hline & {$[0.007]^{* *}$} & {$[0.007]^{* *}$} & {$[0.007]^{* *}$} & {$[0.007]^{* *}$} & {$[0.006]^{* *}$} & {$[0.006]^{* *}$} & {$[0.006]^{*}$} & {$[0.006]+$} \\
\hline \multirow[t]{2}{*}{3 Years after move } & 0.031 & 0.037 & 0.03 & 0.024 & 0.02 & 0.025 & 0.015 & 0.01 \\
\hline & {$[0.008]^{* *}$} & {$[0.008]^{* *}$} & {$[0.008]^{* *}$} & {$[0.008]^{* *}$} & {$[0.007]^{* *}$} & {$[0.006]^{* *}$} & {$[0.007]^{*}$} & {$[0.007]$} \\
\hline \multirow[t]{2}{*}{4 Years after move } & 0.028 & 0.034 & 0.028 & 0.02 & 0.022 & 0.025 & 0.015 & 0.014 \\
\hline & {$[0.010]^{* *}$} & {$[0.009]^{* *}$} & {$[0.009]^{* *}$} & {$[0.009]^{*}$} & {$[0.008]^{* *}$} & {$[0.007]^{* *}$} & {$[0.007]^{*}$} & {$[0.007]+$} \\
\hline \multirow[t]{2}{*}{5 Years after move } & 0.037 & 0.043 & 0.038 & 0.025 & 0.022 & 0.025 & 0.016 & 0.016 \\
\hline & {$[0.011]^{* *}$} & {$[0.010]^{* *}$} & {$[0.011]^{* *}$} & {$[0.010]^{*}$} & {$[0.009]^{*}$} & {$[0.008]^{* *}$} & {$[0.008]+$} & {$[0.008]+$} \\
\hline \multirow[t]{2}{*}{6 Years after move } & 0.027 & 0.035 & 0.029 & 0.02 & 0.024 & 0.028 & 0.019 & 0.02 \\
\hline & {$[0.013]^{*}$} & {$[0.012]^{* *}$} & {$[0.012]^{*}$} & {$[0.012]+$} & {$[0.010]^{*}$} & {$[0.009]^{* *}$} & {$[0.010]^{*}$} & {$[0.010]^{*}$} \\
\hline \multirow[t]{2}{*}{7 Years after move } & 0.043 & 0.049 & 0.044 & 0.024 & 0.022 & 0.025 & 0.016 & 0.011 \\
\hline & {$[0.014]^{* *}$} & {$[0.013]^{* *}$} & {$[0.014]^{* *}$} & {$[0.013]+$} & {$[0.011]+$} & {$[0.011]^{*}$} & [0.011] & {$[0.011]$} \\
\hline \multirow[t]{2}{*}{8 Years after move } & 0.033 & 0.04 & 0.034 & 0.023 & 0.02 & 0.024 & 0.014 & 0.017 \\
\hline & {$[0.016]^{*}$} & {$[0.015]^{* *}$} & {$[0.015]^{*}$} & [0.015] & {$[0.013]$} & {$[0.012]^{*}$} & [0.012] & [0.012] \\
\hline 9 Years after move & 0.061 & 0.069 & 0.062 & 0.04 & 0.052 & 0.056 & 0.047 & 0.052 \\
\hline & {$[0.020]^{* *}$} & {$[0.018]^{* *}$} & {$[0.019]^{* *}$} & {$[0.018]^{*}$} & {$[0.016]^{* *}$} & {$[0.015]^{* *}$} & {$[0.015]^{* *}$} & {$[0.015]^{* *}$} \\
\hline Lagged scores & - & 0.762 & 0.762 & 0.765 & - & 0.732 & 0.731 & 0.732 \\
\hline & - & {$[0.002]^{* *}$} & {$[0.002]^{* *}$} & {$[0.002]^{* *}$} & - & {$[0.002]^{* *}$} & {$[0.002]^{* *}$} & {$[0.002]^{* *}$} \\
\hline Teacher Effects & Yes & Yes & Yes & Yes & Yes & Yes & Yes & Yes \\
\hline School Effects & No & No & Yes & Yes & No & No & Yes & Yes \\
\hline School×Year Effects & No & No & Yes & Yes & No & No & Yes & Yes \\
\hline Observations & 1249122 & 1249122 & 1249122 & 1249122 & 1241150 & 1241150 & 1241150 & 1241150 \\
\hline Prob pre $=0$ & 0.20 & 0.24 & 0.31 & 0.62 & 0.02 & 0.04 & 0.04 & 0.26 \\
\hline Prob post $=0$ & $<0.01$ & $<0.01$ & $<0.01$ & $<0.01$ & $<0.01$ & $<0.01$ & $<0.01$ & $<0.01$ \\
\hline
\end{tabular}

Robust standard errors in brackets clustered at the teacher level.

+ significant at $10 \%$; significant at $5 \%$;* significant at $1 \%$

All models include grade and year fixed effects and controls for student race, gender, parental education, and LEP status. Models also include an indicator for the gender and racial match between the student and the teacher. teacher experience. and the class size. 
Table 5: Estimated Variability of Effects

Math

\begin{tabular}{|c|c|c|c|c|c|c|c|}
\hline \multirow[b]{2}{*}{ Std. Dev. of School Effects } & \multicolumn{2}{|c|}{$\begin{array}{l}\text { Raw Fixed } \\
\text { Effects }\end{array}$} & \multicolumn{2}{|c|}{$\begin{array}{l}\text { Covariance } \\
\text { Estimates }^{\mathrm{a}}\end{array}$} & \multicolumn{3}{|c|}{ Random Effects } \\
\hline & 0.2285 & 0.2285 & 0.0882 & 0.0882 & 0.106 & 0.099 & 0.098 \\
\hline Std. Dev. of Teacher Effects & 0.3503 & 0.3506 & $0.1667^{\mathrm{b}}$ & 0.1498 & 0.19 & 0.141 & 0.142 \\
\hline Std. Dev. of Match Effects & - & 0.1121 & - & 0.0892 & - & 0.1302 & 0.0953 \\
\hline Std. Dev. of Classroom Effects & - & - & - & - & - & - & 0.141 \\
\hline Std. Dev. of residuals & 0.5023 & 0.50704 & - & - & 0.50895 & 0.5076 & 0.4942 \\
\hline \multicolumn{8}{|c|}{ Reading } \\
\hline Std. Dev. of School Effects & 0.2475 & 0.2472 & 0.0504 & 0.0504 & 0.0926 & 0.06547 & 0.0648 \\
\hline Std. Dev. of Teacher Effects & 0.3563 & 0.3564 & $0.1095^{\mathrm{b}}$ & 0.05695 & 0.1107 & 0.08377 & 0.08384 \\
\hline Std. Dev. of Match Effects & - & 0.1182 & - & 0.08785 & - & 0.0777 & 0.05967 \\
\hline Std. Dev. of Classroom Effects & - & - & - & - & - & - & 0.09304 \\
\hline Std. Dev. of residual & 0.5481 & 0.5467 & - & - & 0.61125 & 0.5553 & 0.5499 \\
\hline
\end{tabular}

Notes: The fixed effects and covariance estimates are computed under the assumption that teacher and match effects are not correlated in the sample. Alternately, the random effects model allows for correlations between estimated school, teacher and match effects in small samples.

a. The variance of the school effect is computed as the covariance between the classroom effect across different teachers from the same school. The variance of the teacher effect is computed as the covariance between the classroom effect across schools from the same teacher. Finally, the variance of the match effects is computed as the covariance between the classroom effect within the same teachers at the same school minus the estimated variance of the school and teacher effects.

b. The naive variance of the teacher effect is computed as the covariance between the classroom effects within schools for the same teacher minus the estimated school variance. 
Table 6: Match Quality and Teacher Mobility

Match Effect Math BLUP

Teacher Effect Math BLUP

School Effect Math BLUP

Match Effect Math FE

Log(Salary)

$\%$ freelunch

\% Black

Log(enrollment)

Mean math scores at School

1-3 years Experience

4-9 years Experience

10-25 years Experience

$25+$ Years experience

Licensure score

Advanced degree

Regular licensure

OR for match

Teacher FX

School FX

Year FX

Observations

Robust pval in parenthese

\begin{tabular}{|c|c|c|c|c|c|c|c|c|c|c|c|}
\hline $\begin{array}{c}\text { Exit } \\
\text { Teaching }\end{array}$ & $\begin{array}{l}\text { Switch } \\
\text { Schools }\end{array}$ & $\begin{array}{c}\text { Exit } \\
\text { Teaching }\end{array}$ & $\begin{array}{l}\text { Switch } \\
\text { Schools }\end{array}$ & $\begin{array}{c}\text { Exit } \\
\text { Teaching }\end{array}$ & $\begin{array}{l}\text { Switch } \\
\text { Schools }\end{array}$ & $\begin{array}{c}\text { Exit } \\
\text { Teaching }\end{array}$ & $\begin{array}{l}\text { Switch } \\
\text { Schools }\end{array}$ & $\begin{array}{c}\text { Exit } \\
\text { Teaching }\end{array}$ & $\begin{array}{l}\text { Switch } \\
\text { Schools }\end{array}$ & $\begin{array}{c}\text { Exit } \\
\text { Teaching }\end{array}$ & $\begin{array}{l}\text { Switch } \\
\text { Schools }\end{array}$ \\
\hline 1 & 2 & 3 & 4 & 5 & 6 & 7 & 8 & 9 & 10 & 11 & 12 \\
\hline \multicolumn{4}{|c|}{ Logistic } & \multicolumn{4}{|c|}{ Conditional Logit } & \multicolumn{4}{|c|}{ OLS } \\
\hline $0.942 * *$ & $0.669 * *$ & $0.942 * *$ & $0.681 * *$ & $0.935 * *$ & $0.851 * *$ & $0.946 * *$ & $0.725 * *$ & -0.0090 & $-0.027 * *$ & & \\
\hline$(0.000)$ & 0.000 & $(0.000)$ & 0.000 & $(0.091)$ & $(0.000)$ & $(0.002)$ & 0.000 & $(0.075)$ & $(0.000)$ & & \\
\hline $0.880 * *$ & $1.102+$ & $0.906 * *$ & 1.004 & & & $0.895^{* *}$ & 1.001 & & & & \\
\hline $\begin{array}{c}0.000 \\
0.964 * *\end{array}$ & & $(0.000)$ & & & & $(0.000)$ & $(0.285)$ & & & & \\
\hline \multirow[t]{25}{*}{$(0.000)$} & $\begin{array}{c}0.884 * * \\
0.000\end{array}$ & $\begin{array}{c}1.032 * * \\
(0.008)\end{array}$ & $\begin{array}{c}0.947 * * \\
(0.013)\end{array}$ & $\begin{array}{l}0.9360 \\
(0.269)\end{array}$ & $\begin{array}{c}0.873 * * \\
(0.003)\end{array}$ & & & & & & \\
\hline & & & & & & & & & & $\begin{array}{c}-0.0013 \\
(0.582)\end{array}$ & $\begin{array}{c}-0.0104 * * \\
(0.000)\end{array}$ \\
\hline & & 0.3135 & 0.6139 & 0.2639 & 0.6557 & 0.3003 & 0.6518 & -0.2820 & -0.0124 & -0.2790 & -0.0147 \\
\hline & & $\begin{array}{l}(0.000) \\
1.0763\end{array}$ & $\begin{array}{c}(0.000) \\
0.9347\end{array}$ & $\begin{array}{c}(0.000) \\
1.1241\end{array}$ & $\begin{array}{c}(0.120) \\
1.9079\end{array}$ & $\begin{array}{c}0.000 \\
1.1549\end{array}$ & $\begin{array}{l}(0.011) \\
1.1052\end{array}$ & $\begin{array}{c}(0.000) \\
0.0270\end{array}$ & $\begin{array}{c}(0.432) \\
0.0079\end{array}$ & $\begin{array}{l}(0.000) \\
0.0268\end{array}$ & $\begin{array}{l}(0.355) \\
0.0076\end{array}$ \\
\hline & & $(0.245)$ & $(0.591)$ & $(0.300)$ & $(0.001)$ & $(0.110)$ & $(0.681)$ & $(0.220)$ & $(0.437)$ & $(0.224)$ & $(0.457)$ \\
\hline & & 1.1445 & 2.2524 & 1.8908 & 3.0526 & 1.3152 & 11.7870 & 0.1140 & 0.1150 & 0.1090 & 0.1150 \\
\hline & & $(0.012)$ & 0.000 & $(0.012)$ & $(0.000)$ & $(0.261)$ & $(0.000)$ & $(0.102)$ & $(0.002)$ & (0.121) & $(0.002)$ \\
\hline & & 0.9911 & 0.9472 & 1.1806 & 0.9593 & 1.1309 & 5.1500 & 0.0435 & 0.0282 & 0.0423 & 0.0277 \\
\hline & & (0.729) & (0.319) & (0.093) & $(0.644)$ & (0.133) & $(0.000)$ & $(0.045)$ & (0.009) & $(0.050)$ & (0.010) \\
\hline & & 0.7922 & 0.7827 & 0.8057 & 0.7161 & 0.8049 & 0.9191 & -0.0425 & -0.0062 & -0.0439 & -0.0070 \\
\hline & & $(0.000)$ & $(0.001)$ & (0.011) & $(0.006)$ & $(0.000)$ & $(0.604)$ & (0.003) & $(0.342)$ & $(0.002)$ & $(0.282)$ \\
\hline & & 1.1688 & 0.9892 & 3.9196 & 0.8033 & 1.2105 & 1.0260 & 0.2290 & -0.0026 & 0.2280 & -0.0027 \\
\hline & & $(0.000)$ & $(0.887)$ & 0.000 & $(0.020)$ & $(0.000)$ & $(0.743)$ & $(0.000)$ & $(0.692)$ & $(0.000)$ & $(0.680)$ \\
\hline & & 1.2461 & 0.9065 & 5.4739 & 0.7945 & 1.3284 & 0.9818 & 0.2900 & -0.0009 & 0.2890 & -0.0010 \\
\hline & & $(0.000)$ & $(0.244)$ & 0.000 & (0.086) & $(0.000)$ & (0.838) & $(0.000)$ & (0.916) & $(0.000)$ & $(0.903)$ \\
\hline & & 1.1468 & 0.7182 & 3.7886 & 0.9195 & 1.2700 & 0.8187 & 0.2600 & 0.0120 & 0.2590 & 0.0117 \\
\hline & & (0.011) & $(0.000)$ & 0.000 & (0.673) & $(0.000)$ & $(0.044)$ & $(0.000)$ & $(0.241)$ & $(0.000)$ & $(0.255)$ \\
\hline & & 1.8626 & 0.4471 & 3.1582 & 0.9926 & 2.1085 & 0.5066 & 0.2170 & 0.0115 & 0.2170 & 0.0110 \\
\hline & & $(0.000)$ & $(0.000)$ & $(0.000)$ & $(0.978)$ & 0.000 & $(0.000)$ & $(0.000)$ & (0.337) & $(0.000)$ & (0.358) \\
\hline & & 1.0278 & 1.0514 & 0.9707 & 1.7437 & 1.0152 & 1.0324 & -0.0098 & 0.0167 & -0.0104 & 0.0178 \\
\hline & & (0.028) & (0.035) & (0.891) & (0.184) & $(0.249)$ & $(0.217)$ & (0.789) & $(0.326)$ & (0.778) & (0.301) \\
\hline & & 1.2423 & 1.1264 & 0.8816 & 1.3840 & 1.2386 & 1.1411 & -0.0244 & 0.0072 & -0.0216 & 0.0075 \\
\hline & & $(0.000)$ & $(0.030)$ & $(0.287)$ & $(0.142)$ & 0.000 & $(0.023)$ & $(0.206)$ & (0.382) & $(0.262)$ & $(0.366)$ \\
\hline & & 0.4644 & 1.6753 & 2.2255 & 0.6676 & 0.4700 & 1.7986 & 0.0828 & -0.0061 & 0.0815 & -0.0066 \\
\hline & & $(0.000)$ & $(0.000)$ & $(0.000)$ & $(0.127)$ & $(0.000)$ & $(0.000)$ & $(0.000)$ & $(0.416)$ & $(0.000)$ & $(0.379)$ \\
\hline 0.942 & 0.670 & 0.942 & 0.682 & 0.935 & 0.851 & 0.947 & 0.725 & 0.971 & 0.346 & 0.996 & 0.746 \\
\hline $\mathrm{N}$ & $\mathrm{N}$ & $\mathrm{N}$ & $\mathrm{N}$ & $\mathrm{Y}$ & $\mathrm{Y}$ & $\mathrm{N}$ & $\mathrm{N}$ & $\mathrm{Y}$ & $\mathrm{Y}$ & $\mathrm{Y}$ & $\mathrm{Y}$ \\
\hline $\mathrm{N}$ & $\mathrm{N}$ & $\mathrm{N}$ & $\mathrm{N}$ & $\mathrm{N}$ & $\mathrm{N}$ & $\mathrm{Y}$ & $\mathrm{Y}$ & $\mathrm{Y}$ & $\mathrm{Y}$ & $\mathrm{Y}$ & $\mathrm{Y}$ \\
\hline $\mathrm{Y}$ & $\mathrm{Y}$ & $\mathrm{Y}$ & $\mathrm{Y}$ & $Y$ & $\mathrm{Y}$ & $\mathrm{Y}$ & $\mathrm{Y}$ & $Y$ & $\mathrm{Y}$ & $Y$ & $\mathrm{Y}$ \\
\hline 74,676 & 74,676 & 74,154 & 74,154 & 44,215 & 14,142 & 74,032 & 59,326 & 74,154 & 74,154 & 74,008 & 74,008 \\
\hline
\end{tabular}

do indicate statistical significance for match school and teacher effect variables only. + significant at $10 \%$; * significant at 5\%; ** significant at $1 \%$ 
Table 7: The Correlates of Match Quality

Standardized BLUPS

Standardized Raw Fixed Effects

Teacher: 1-3 years exp.

\begin{tabular}{cccccccccc}
\hline Math & Reading & Math & Reading & & Math & & Reading & Math & \multicolumn{2}{c}{ Reading } \\
\hline 1 & 2 & 3 & 4 & & 5 & 6 & 7 & 8 \\
\hline 0.059 & 0.022 & 0.043 & 0.015 & & 0.031 & 0.025 & 0.052 & 0.052 \\
{$[0.012]^{* *}$} & {$[0.011]^{*}$} & {$[0.012]^{* *}$} & {$[0.010]$} & & {$[0.017]+$} & {$[0.017]$} & {$[0.036]$} & {$[0.031]+$} \\
0.094 & 0.108 & 0.061 & 0.037 & & 0.035 & 0.028 & 0.056 &
\end{tabular}

Teacher: 4-10 years exp.

0.094

0.108

0.061

0.037

0.035

0.028

0.056

0.077

$[0.017]^{* *}$

$[0.016]^{* *}[0.020]^{* *} \quad[0.018]^{*}$

[0.016]*

[0.018] [0.044]

[0.039]*

Teacher: 10-25 years exp.

0.142

0.247

0.081

0.028

0.03

0.065

0.122

Teacher: 25+ years exp.

$[0.019]^{* *}\left[\begin{array}{llll}0.018 & ]^{* *} & {[0.024]^{* *}} & {[0.022]^{*}}\end{array}\right.$

$[0.016]+[0.018]+[0.028]^{*}$

$[0.046]^{* *}$

0.388

0.088

0.049

0.048

0.031

0.084

0.132

Teacher: White

0.201

$0.023]^{* *}$

$[0.028]^{* *}[0.024]^{*}$

$[0.017]^{* *}$

$[0.018]+[0.050]+$

$[0.073]^{* *} \quad[0.081]$

Teacher: Black

$-0.004$

[0.076]

$-0.048$

[0.085]
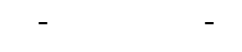

$-0.066$

$-0.057$

[0.038]+

[0.035]

$-0.059$

[0.039]

$-0.055$

-

[0.036]

$-$

Teacher: Certified

0.172

$[0.033]^{* *} \quad[0.032]^{* *}$

$[0.033]^{* *}$

0.135

Teacher: Regular license

0.07

0.077

0.019

$[0.010]^{* *}$

$[0.010]^{* *}$

[0.021]

0.014

0.021

0.051

0.024

$-0.002$

[0.018]

[0.022]

0.025

[0.018]

$[0.010]^{* *}$

[0.011]*

[0.009]

$-0.007$

$-0.015$

$-0.024$

[0.009]+

$-0.024$

$[0.008]^{* *}$

[0.007]

$\begin{array}{ll}-0.019 & 0.039\end{array}$

$-0.048$

$-0.057$

[0.028]

[0.026]

[0.022]*

[0.022]*

0.014

0.002

$-0.092$

$-0.192$

[0.020]

[0.018]

[0.054]+

$[0.042]^{* *}$

$-0.152$

$-0.111$

$-0.052$

$-0.157$

[0.087]+

[0.102]

[0.052]

$[0.039]^{* *}$

$-0.067$

$-0.066$

$-0.063$

$-0.171$

[0.083]

[0.098]

[0.053]

$[0.040]^{* *}$

$-0.098$

$-0.103$

$-0.024$

0.052

[0.082]

[0.096]

[0.031]

[0.030]+

$-0.167$

$-0.013$

0.019

$-0.011$

[0.080]*

[0.071]

School: \%Free lunch

[0.031]

[0.030]

0.001

$-0.015$

0.049

0.025

[0.029]

[0.025]

$[0.014]^{* *}$

$[0.014]+$

0.087

0.049

$[0.033]^{* *}[0.029]+$

[0.005]

$-0.005$

[0.005]

$-0.005$

[0.012]

$-0.007$

[0.012]

$-0.027$

$-0.01$

[0.033]

[0.029]

$-0.042$

$-0.012$

[0.031]

[0.027]

$-0.032$

$-0.004$

[0.032]

[0.027]

$-0.021$

$-0.02$

[0.019]

[0.018]

$-0.024$

$-0.012$

[0.022]

[0.021]

0.003

0.008

[0.009]

[0.009]

88944
0
$\mathrm{~N}$

88768
0

88944

0.2

0.21

N

0.003

[0.034]

$-0.026$

[0.014]+

0.004

[0.070]

0.008

[0.043]

$-0.252$

[0.193]

$-0.24$

[0.187]

$-0.215$

[0.186]

$-0.205$

[0.125]

$-0.079$

[0.051]

0.009

[0.051]

[0.050]

$\begin{array}{llll}0.02 & 0.02 & 0.82 & 0.86\end{array}$

Teacher Effects

$\mathrm{N}$

$\mathrm{Y}$

$\mathrm{Y}$

Robust standard errors in brackets

+ significant at 10\%; * significant at 5\%; ** significant at $1 \%$

Omitted categories are "large city" and "zero years of experience". 
Table 8: Match Quality and Teacher School Combinations

\section{Effective * Mean(Effective at school)}

Effective * Mean(cognitive at school)

Effective * Mean(Credentialed at school)

Cognitive * Mean(Effective at school)

Cognitive * Mean(Cognitive at school)

Cognitive * Mean(Credentialed at school)

Credentialed * Mean(Effective at school)

Credentialed * Mean(Cognitive at school)

Credentialed * Mean(Credentialed at school)

Effective * Suburban, High Achieving, White School

Effective * Rural, low income, White School

Effective * Urban, Low Achieving, Poor, Black School

Cognitive * Suburban, High Achieving, White School

Cognitive * Rural, low income, White School

Cognitive * Urban, Low Achieving, poor, Black School

Credentialed * Suburban, High Achieving, White School

Credentialed * Rural, low income, White School

Credentialed * Urban, Low Achieving, poor, Black School

\begin{tabular}{cc} 
math & read \\
\hline-0.00905 & -0.0129 \\
{$[0.0296]$} & {$[0.0324]$} \\
$-0.142 * *$ & -0.0383 \\
{$[0.0407]$} & {$[0.0446]$} \\
$\mathbf{0 . 0 8 9 8 * *}$ & $\mathbf{0 . 0 6 0 7} *$ \\
{$[\mathbf{0 . 0 2 5 9}]$} & {$[\mathbf{0 . 0 2 8 3}]$} \\
-0.00593 & -0.00553 \\
{$[0.0116]$} & {$[0.0126]$} \\
$-0.0472 * *$ & 0.0297 \\
{$[0.0169]$} & {$[0.0184]$} \\
-0.0137 & 0.0042 \\
{$[0.0115]$} & {$[0.0126]$} \\
$-0.0306 *$ & -0.000829 \\
{$[0.0134]$} & {$[0.0147]$} \\
$-\mathbf{0 . 0 4 1 7} *$ & $\mathbf{- 0 . 0 4 7 6 *}$ \\
{$[\mathbf{0 . 0 1 8 4}]$} & {$[\mathbf{0 . 0 2 0 1}]$} \\
-0.0133 & 0.00546 \\
{$[0.0124]$} & {$[0.0136]$} \\
$\mathbf{- 0 . 0 6 5 8 * *}$ & $\mathbf{- 0 . 0 4 8 6 * *}$ \\
{$[\mathbf{0 . 0 1 1 6}]$} & {$[\mathbf{0 . 0 1 2 6}]$} \\
$-0.0289 *$ & -0.00669 \\
{$[0.0145]$} & {$[0.0158]$} \\
$-0.0870 * *$ & -0.0191 \\
{$[0.0140]$} & {$[0.0154]$} \\
0.00638 & 0.0083 \\
{$[0.00479]$} & {$[0.00523]$} \\
0.00911 & -0.00234 \\
{$[0.00687]$} & {$[0.00751]$} \\
0.00196 & 0.00252 \\
{$[0.00663]$} & {$[0.00724]$} \\
-0.00175 & -0.0021 \\
{$[0.00551]$} & {$[0.00602]$} \\
0.00427 & 0.0127 \\
{$[0.00789]$} & {$[0.00862]$} \\
$\mathbf{0 . 0 2 1 6 * *}$ & $\mathbf{0 . 0 1 9 8} *$ \\
{$[\mathbf{0 . 0 0 7 5 3 ]}$} & {$[\mathbf{0 . 0 0 8 2 3}]$} \\
& \\
&
\end{tabular}

Effective* Strong Leadership

Effective*Well Resourced

Effective* Time

Effective* Professional Development

Cognitive* Strong Leadership

Cognitive*Well Resourced

Cognitive* Time

Cognitive* Professional Development

Credentials* Strong Leadership

Credentials*Well Resourced

Credentials* Time

Credentials* Professional Development

\begin{tabular}{cc} 
math & read cont'd \\
\hline-0.00462 & -0.00196 \\
{$[0.0109]$} & {$[0.0119]$} \\
$-0.0264 *$ & -0.0105 \\
{$[0.0120]$} & {$[0.0131]$} \\
0.00874 & 0.012 \\
{$[0.0129]$} & {$[0.0141]$} \\
$\mathbf{0 . 0 7 9 6} * *$ & $\mathbf{0 . 0 3 5 4} *$ \\
{$[\mathbf{0 . 0 1 5 4}]$} & {$[\mathbf{0 . 0 1 6 9 ]}$} \\
$\mathbf{- 0 . 0 1 0 1} *$ & $\mathbf{- 0 . 0 0 9 3 3 +}$ \\
{$[\mathbf{0 . 0 0 4 6 4}]$} & {$[\mathbf{0 . 0 0 5 0 8}]$} \\
0.00441 & 0.00402 \\
{$[0.00567]$} & {$[0.00620]$} \\
-0.0045 & 0.00205 \\
{$[0.00606]$} & {$[0.00662]$} \\
0.00889 & 0.0113 \\
{$[0.00663]$} & {$[0.00726]$} \\
$-0.0178 * *$ & -0.00671 \\
{$[0.00539]$} & {$[0.00590]$} \\
-0.00388 & -0.00121 \\
{$[0.00680]$} & {$[0.00743]$} \\
-0.00551 & -0.00556 \\
{$[0.00702]$} & {$[0.00767]$} \\
$\mathbf{- 0 . 0 2 5 3 * *}$ & $-\mathbf{0 . 0 2 0 6} *$ \\
{$[\mathbf{0 . 0 0 7 5 5}]$} & {$[\mathbf{0 . 0 0 8 2 6}]$} \\
& \\
$1,133,980$ & $1,127,033$ \\
& \\
$5.36 E-08$ & 0.0315 \\
$6.73 E-09$ & 0.0416 \\
0 & 0.00162 \\
\hline &
\end{tabular}

Observations

Pr[ttype_int $]=0$

Pr[stype_int $]=0$

$\operatorname{Pr}[$ sstype_int $]=0$

0.00162

Robust standard errors in brackets

** $\mathrm{p}<0.01, * \mathrm{p}<0.05,+\mathrm{p}<0.1$

All models include teacher and school fixed effects and control for lagged student achievement 

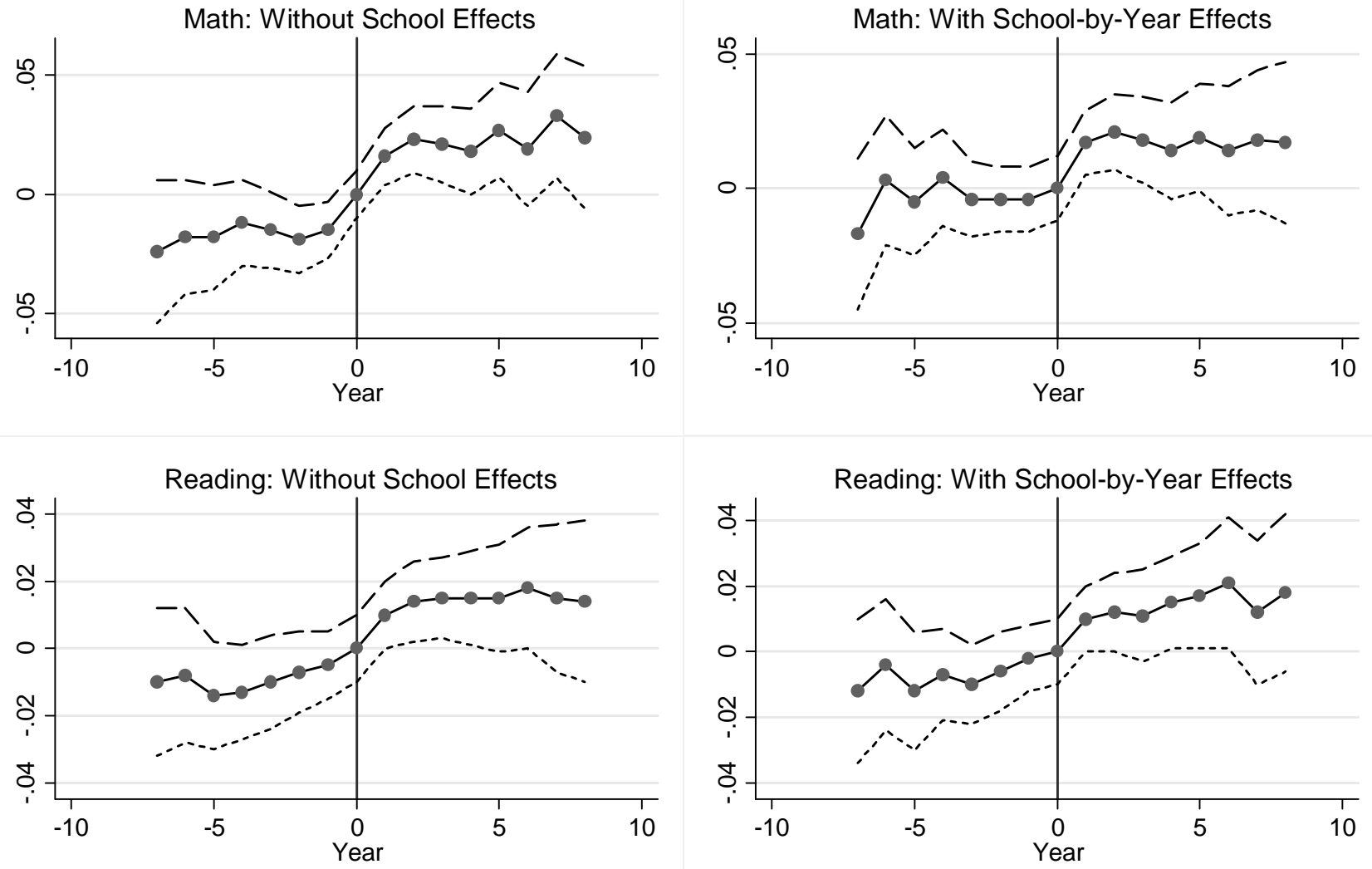

Figure 1: Change in Teacher Math Value-added Before and After a Move and the 95 Percent Confidence Interval 


\section{Appendix Tables and Figures}

\section{Appendix Table A1: Teacher and School Factors}

Math Estimated Value-Added

Reading Estimated Value-Added

Fully Certified

Average score on Licensure Exams

Years of Experience

Advanced Degree

75th percentile of the SAT distribution at College

Fully Licensed

\begin{tabular}{|c|c|c|c|c|}
\hline 1 & 2 & 3 & 4 & Uniqueness \\
\hline 0.5551 & 0.0554 & 0.0545 & 0.0012 & 0.6858 \\
\hline 0.5534 & 0.0087 & 0.0413 & 0.0033 & 0.692 \\
\hline 0.0184 & 0.1316 & 0.1161 & 0.0809 & 0.9623 \\
\hline 0.0326 & 0.5485 & -0.0439 & 0.0326 & 0.6951 \\
\hline 0.0512 & -0.1082 & 0.5006 & 0.0417 & 0.7334 \\
\hline-0.01 & 0.0841 & 0.3209 & 0.162 & 0.8636 \\
\hline 0.0219 & 0.5296 & -0.0416 & -0.005 & 0.7173 \\
\hline 0.0566 & -0.0251 & 0.3782 & -0.0712 & 0.8481 \\
\hline
\end{tabular}

Factor 1: High value-added teachers (effective) $(\sigma=0.81)$

Factor 2: High test score and selective college (cognitive) $(\sigma=0.42)$

Factor 3: Experienced, fully licensed and fully certified (credentials) $(\sigma=0.40)$

Percent white students at school

Percent black students at schools

Percent on free lunch

Mean math scores

Mean reading scores

Mean parental education

City

Rural

Total enrollment

\begin{tabular}{cccccc}
\multicolumn{5}{c}{ Factor } & \\
\cline { 1 - 4 } 1 & 2 & 3 & 4 & 5 & Uniqueness \\
\hline 0.3993 & 0.7873 & -0.3828 & 0.091 & 0.031 & 0.065 \\
-0.3556 & -0.7592 & 0.4077 & -0.1415 & 0.0519 & 0.1083 \\
-0.5794 & -0.5389 & 0.0909 & -0.4711 & -0.1633 & 0.1169 \\
0.8808 & 0.3504 & -0.0099 & 0.2295 & -0.1021 & 0.0382 \\
0.8954 & 0.3493 & 0.0101 & 0.2327 & 0.0147 & 0.0218 \\
0.7023 & 0.1071 & 0.3153 & 0.459 & 0.177 & 0.1538 \\
0.045 & -0.1869 & 0.6289 & 0.0288 & 0.0157 & 0.5665 \\
-0.0331 & 0.1102 & -0.5789 & -0.1118 & 0.008 & 0.639 \\
0.194 & 0.0682 & 0.0967 & 0.4311 & -0.0129 & 0.7623
\end{tabular}

Factor 1: Suburban, high achieving, high parental education, affluent, white students $(\sigma=0.95)$

Factor 2: Rural, medium achieving, affluent, white students $(\sigma=0.93)$

Factor 3: Urban, low achieving, low income, non-white students $(\sigma=0.51)$

\begin{tabular}{|c|c|c|c|c|c|c|}
\hline \multirow[b]{2}{*}{ Question } & \multicolumn{5}{|c|}{ Factor } & \multirow[b]{2}{*}{ Uniqueness } \\
\hline & 1 & 2 & 3 & 4 & 5 & \\
\hline Teachers have reasonable student loads. & 0.1417 & 0.1877 & 0.5683 & 0.0783 & 0.031 & 0.6081 \\
\hline Teachers are protected from duties that interfere with teaching. & 0.3488 & 0.2315 & 0.6701 & 0.1308 & 0.0462 & 0.3511 \\
\hline Teachers have time to collaborate with colleagues & 0.1729 & 0.1968 & 0.5757 & -0.3025 & 0.0383 & 0.4851 \\
\hline Time is provided for professional development. & 0.2776 & 0.216 & 0.3985 & -0.6199 & 0.0056 & 0.3299 \\
\hline Leadership tries to address concerns about time & 0.7442 & 0.2 & 0.4263 & 0.1789 & 0.0217 & 0.1641 \\
\hline Teachers have quiet space to work individually & 0.1314 & 0.566 & 0.2647 & 0.0778 & 0.0011 & 0.5456 \\
\hline Teachers have sufficient office supplies. & 0.2736 & 0.5754 & 0.2058 & 0.129 & 0.1198 & 0.5169 \\
\hline Classrooms/labs have current technology. & 0.1901 & 0.6579 & 0.1088 & -0.2193 & 0.041 & 0.4565 \\
\hline Teachers have reliable communication technology & 0.1782 & 0.7121 & 0.154 & 0.0954 & 0.014 & 0.4222 \\
\hline School environment is clean and safe. & 0.4246 & 0.5251 & 0.1522 & -0.0895 & 0.0508 & 0.3937 \\
\hline Leadership tries to address concerns about facilities & 0.7551 & 0.3876 & 0.2202 & 0.1697 & 0.0018 & 0.1415 \\
\hline Principal is a strong, supportive leader. & 0.8701 & 0.1612 & 0.1464 & -0.119 & 0.1012 & 0.1577 \\
\hline Leaders shield teachers from disruptions. & 0.7358 & 0.2583 & 0.334 & -0.0795 & 0.0556 & 0.2371 \\
\hline Administrators give priority to supporting teachers & 0.8625 & 0.1861 & 0.2034 & -0.1245 & 0.0397 & 0.1519 \\
\hline Teachers are held to high standards. & 0.6411 & 0.2602 & 0.1144 & -0.2135 & 0.1496 & 0.3669 \\
\hline New teachers have effective mentors. & 0.58 & 0.2504 & 0.1252 & -0.2617 & 0.026 & 0.466 \\
\hline Leaders try to address concerns about leadership & 0.8828 & 0.1963 & 0.2033 & 0.1829 & 0.0313 & 0.0915 \\
\hline Teachers are centrally involved in decision-making & 0.7446 & 0.2004 & 0.2649 & 0.2089 & 0.2898 & 0.1955 \\
\hline Teachers are recognized as educational experts & 0.7277 & 0.1983 & 0.2658 & 0.1623 & 0.3226 & 0.2216 \\
\hline Parents have many avenues to express concerns. & 0.6153 & 0.211 & 0.0706 & 0.1903 & 0.0343 & 0.4655 \\
\hline There is an atmosphere of mutual respect at school & 0.8205 & 0.2229 & 0.1818 & 0.1369 & 0.0913 & 0.202 \\
\hline Resources are available for professional development & 0.3436 & 0.3042 & 0.226 & 0.5956 & 0.0541 & 0.378 \\
\hline Leadership tries to provide quality professional development & 0.6664 & 0.2258 & 0.1394 & 0.4731 & 0.0282 & 0.2469 \\
\hline
\end{tabular}

Factor 1: Strong leadership, good school culture, high standards $(\sigma=0.97)$

Factor 2: Well resourced $(\sigma=0.84)$

Factor 3: Teachers have time $(\sigma=0.80)$

Factor 4: Emphasis placed on professional development $(\sigma=0.81)$ 


\section{Appendix Table A2: Relationship between teacher ethnicity and match quality}

\begin{tabular}{|c|c|c|c|c|}
\hline & 1 & 2 & 3 & 4 \\
\hline & Math & Reading & Math & Reading \\
\hline \multirow[t]{2}{*}{ Lagged Achievement } & $0.805^{* *}$ & $0.781^{* *}$ & $0.798^{* *}$ & $0.773 * *$ \\
\hline & {$[0.00124]$} & {$[0.00142]$} & {$[0.00124]$} & [0.00143] \\
\hline \multirow[t]{2}{*}{ White teacher } & 0.0575 & 0.0201 & & \\
\hline & {$[0.0719]$} & [0.0487] & & \\
\hline \multirow[t]{2}{*}{ Black teacher } & $-0.101^{* *}$ & $-0.0404 *$ & & \\
\hline & {$[0.0251]$} & {$[0.0164]$} & & \\
\hline \multirow[t]{2}{*}{ White teacher X Percent White teachers at school } & -0.0677 & -0.0198 & -0.0147 & 0.0238 \\
\hline & {$[0.0900]$} & {$[0.0604]$} & {$[0.0234]$} & {$[0.0204]$} \\
\hline \multirow[t]{2}{*}{ Black teacher X Percent Black teachers at school } & $0.237 *$ & $0.126 *$ & -0.00135 & -0.00402 \\
\hline & {$[0.0964]$} & {$[0.0641]$} & {$[0.0609]$} & {$[0.0540]$} \\
\hline \multirow[t]{2}{*}{ Black X Suburban, High Achieving, Affluent, White School } & -0.00873 & -0.0112 & 0.0251 & 0.00193 \\
\hline & {$[0.0177]$} & {$[0.0112]$} & {$[0.0377]$} & {$[0.0195]$} \\
\hline \multirow[t]{2}{*}{ Black X Rural, Medium Achieving, low income, White School } & 0.0252 & 0.0265 & 0.0333 & 0.0429 \\
\hline & {$[0.0275]$} & {$[0.0170]$} & {$[0.0390]$} & {$[0.0300]$} \\
\hline \multirow[t]{2}{*}{ Black X Urban, Low Achieving, low income, Black School } & -0.000445 & 0.0207 & 0.00657 & 0.0403 \\
\hline & [0.0243] & {$[0.0145]$} & [0.0459] & {$[0.0278]$} \\
\hline \multirow[t]{2}{*}{ White X Suburban, High Achieving, Affluent, White School } & -0.00464 & -0.00602 & 0.0141 & -0.00278 \\
\hline & {$[0.0170]$} & {$[0.0108]$} & [0.0363] & {$[0.0191]$} \\
\hline \multirow[t]{2}{*}{ White X Rural, Medium Achieving, low income, White School } & 0.0199 & 0.0268 & $0.0619+$ & $0.0488+$ \\
\hline & {$[0.0266]$} & {$[0.0164]$} & [0.0361] & {$[0.0274]$} \\
\hline \multirow[t]{2}{*}{ White X Urban, Low Achieving, low income, Black School } & -0.00669 & 0.0141 & 0.00993 & 0.0376 \\
\hline & [0.0232] & {$[0.0138]$} & [0.0441] & {$[0.0264]$} \\
\hline Grade and year FX & $\mathrm{y}$ & $\mathrm{y}$ & $\mathrm{y}$ & $\mathrm{y}$ \\
\hline School FX & $\mathrm{y}$ & $\mathrm{y}$ & $\mathrm{y}$ & $\mathrm{y}$ \\
\hline Teacher FX & $\mathrm{n}$ & $\mathrm{n}$ & $\mathrm{y}$ & $\mathrm{y}$ \\
\hline Observations & $1,322,810$ & $1,314,602$ & $1,322,810$ & $1,314,602$ \\
\hline $\operatorname{Pr}($ Ethnicity interactions are all=0) & $<0.000$ & $<0.000$ & 0.469 & 0.438 \\
\hline
\end{tabular}

Robust standard errors in brackets

${ }^{* *} \mathrm{p}<0.01, * \mathrm{p}<0.05,+\mathrm{p}<0.1$ 